\title{
OS SISTEMAS DE ESPAÇOS LIVRES NA CONSTITUIÇÃO DA FORMA URBANA CONTEMPORANEA NO BRASIL: PRODUÇÃO E APROPRIAÇÃO (QUAPÁ-SEL II)
}

THE OPEN SPACES SYSTEMS IN THE BRAZILIAN URBAN FORM CONSTITUTION: PRODUCTION AND APPROPRIATION (QUAPÁ-SEL II)

Silvio Soares Macedo

Professor Titular do Paisagismo do Departamento de Projeto FAUUSP, Coordenador Laboratório QUAPÁ - Quadro do Paisagismo no Brasil / AUP/FAUUSP

email: ssmduck@usp.br

Eugenio Fernandes Queiroga

Professor Livre docente de Paisagismo do Departamento Projeto da FAUUSP,

Vice-coordenador do Laboratório QUAPÁ - Quadro de Paisagismo no Brasil

email: queiroga@usp.br

Fany Cutcher Galender

Professora Arquiteta - PMSP/FAUUSP, pesquisadora Laboratório QUAPÁ -

Quadro de Paisagismo no Brasil

email: fgalender@uol.com.br

Ana Cecília de Arruda Campos

Professora Doutora FAUUSP, arquiteta paisagista pesquisadora Laboratório QUAPÁ Quadro de Paisagismo no Brasil

email: arrudacampos@terra.com.br

Vanderli Custódio

Professora e pesquisadora do IEB, professora FFLCH/USP, pesquisadora Laboratório QUAPÁ - Quadro de Paisagismo no Brasil

email: vanderli@usp.br

\section{Helena Degreas}

Professora Arquiteta da FMU, pesquisadora Laboratório QUAPÁ - Quadro de Paisagismo no Brasil

email: hdegreas@uol.com.br

Fabio Mariz Gonçalves

Professor Doutor Arquiteto do Paisagismo do AUP/FAUUSP, pesquisador Laboratório QUAPÁ - Quadro de Paisagismo no Brasil

email: fmgoncalves@usp.br 


\title{
RESUMO
}

Esta proposta é continuação do projeto temático de pesquisa "Os Sistemas de Espaços Livres e a Constituição da Esfera Pública Contemporânea no Brasil", desenvolvido nos anos de 2006-2011 no Laboratório QUAPÁ da FAUUSP em conjunto com o Grupo de Pesquisa "Requalificação Urbana" do CEATEC/ PUC-Campinas, processo FAPESP n. 2006/56623-2 com o envolvimento da Rede Nacional de Pesquisa QUAPÁ-SEL. Trata-se de novo Projeto Temático que visa investigar as relações entre os sistemas de espaços livres e a produção da forma urbana das cidades brasileiras na atualidade. O objeto é complexo (MORIN, 2008): não são os espaços livres nem a forma urbana em si, mas as relações que se estabelecem entre ambos que constituem o foco desta pesquisa. Tais relações constituem sistema, apresentam estrutura e organização que contêm em seu interior, dialeticamente, as relações que a estabelecem e que a desestabilizam. Impõe-se abordagem crítica para apreender o processo socioespacial de constituição das formas, e o que é comum à produção do espaço a nível nacional e para cada local investigado. Aprofunda-se o entendimento do papel dos principais agentes da produção do objeto investigado - do espaço concebido ao espaço vivido (LEFĖBVRE, 1974) - e estabelecer critérios de qualidade que considerem as especificidades locais - do clima às manifestações culturais - e as possibilidades de arranjo dos espaços livres e edificados integrantes do sistema espacial quanto às suas formas, funções e apropriações. Não se trata de criar manual da boa forma urbana, mas de estabelecer princípios teóricos e consolidar métodos de avaliação contribuindo para as diversas escalas de planejamento e de projeto do espaço urbano, com ênfase na vida pública.

\section{Palavras-chave: Sistema de espaços livres, Forma urbana, Cidade brasileira}

\begin{abstract}
This proposal continues the thematic research project "The Open Spaces Systems and the Constitution of the Contemporary Public Sphere in Brazil", developed by the QUAPÁ Laboratory at FAUUSP together with the Urban Renewal Research Group at CEATEC-PUC-Campinas, FAPESP process n ${ }^{\circ}$ 2006/56623-2 in the years 2006-2011. It is a new thematic research project that aims to investigate the relationship between the open spaces systems and the urban form production in the Brazilian cities today. The object is a complex one (MORIN, 2008): it is not the open spaces, neither the urban form itself, but the relationship established between them that are the focus of this research. This relationship constitutes a system, presents a structure, and an organization which contains, dialectically, the relationship that establishes and destabilizes it. A critical approach is mandatory in order to comprehend the social and spatial process that constitutes the urban forms, and what it is common in national basis and for each investigated area. Continuing the national research network QUAPÁ-SEL, the objective is to understand the main stakeholders' role that produces the investigated object - the conceived space and the living space (LEFĖBVRE, 1974) - and to establish quality criteria that considered the local specificities - from weather to cultural manifestations - and the open spaces and buildings arrangements possibilities that integrated the spatial system related to forms, functions and appropriations. It is not a goal to develop another good urban form guide, but to establish theoretical principles and consolidate evaluation methods to contribute to urban planning, with emphasis in public life.
\end{abstract}

Keywords: Open spaces systems, Urban form, Brazilian city 


\section{INTRODUÇÃO}

Este projeto de pesquisa dá continuidade ao Projeto Temático de Pesquisa "Os Sistemas de Espaços Livres e a Constituição da Esfera Pública Contemporânea no Brasil - QUAPÁ-SEL". Tal projeto foi concluído no quadriênio entre março de 2007 e abril de 2011, sendo formulado pelo Laboratório QUAPÁ da FAUUSP, e teve como coordenadores nacionais os doutores Silvio Soares Macedo e Eugenio Queiroga (respectivamente coordenador e vice-coordenador do Laboratório QUAPÁ). O QUAPÁ-SEL foi apoiado, no Estado de São Paulo, pela FAPESP (Projeto Temático de Pesquisa e bolsas de iniciação científica, mestrados e doutorados, para vários integrantes do projeto, orientados por Macedo e Queiroga) pelo CNPq (bolsas de produtividade em pesquisa - ambos - e bolsas de iniciação científica para orientandos) e da CAPES (bolsas de mestrado e outros auxílios a integrantes do projeto).

O QUAPÁ-SEL criou e consolidou a maior rede nacional de pesquisa na subárea de Paisagismo, contando, atualmente com núcleos de pesquisadores nas seguintes universidades: UFSM, UFSC, UFPR, USP, PUC-Campinas, UFRJ, UFMG, UFES, UFAL, UFPE, UFRN, UNIFOR, UNAMA e UFMS. Nestes núcleos foram realizadas inúmeras pesquisas desde o nível da iniciação científica até mestrados e doutorados. Realizaram-se 23 oficinas de pesquisa em todas as regiões do país e, até 2010, foram 5 Colóquios QUAPÁ-SEL - encontros anuais dos pesquisadores da Rede QUAPÁ-SEL. Os resultados parciais da pesquisa foram publicados na forma de artigos em revistas científicas da área, inclusive em número especial da Revista Paisagem e Ambiente (n. 26); no livro organizado por Vera Tângari, Rubens de Andrade e Mônica Schlee (2009) e em vários trabalhos apresentados em eventos científicos internacionais - ISUF e IFLA; e nacionais - ENEPEAs, ENANPARQ e ENANPURs.

Os resultados finais constituirão três livros, o dedicado à apresentação do quadro sobre os sistemas de espaços livres das cidades brasileiras (no prelo), o que apresenta os resultados do V Colóquio QUAPÁ-SEL (no prelo) e o terceiro, de síntese, apresentando os avanços conceituais e de método que permitem estabelecer princípios de avaliação da qualidade de sistemas de espaços livres com intuito de subsidiar a formulação de políticas de intervenção referentes à qualificação de sistemas de espaços livres urbanos no Brasil (em processo de avaliação pela Edusp).

Livro 1 - Quadro do sistema de espaços livres nas cidades brasileiras. Coletânea de textos finais produzidos pelos nossos parceiros de todo o Brasil, que trazem sínteses formuladas por cada grupo de pesquisa sobre o sistema de espaço livres de sua cidade.

Livro 2 - Sistema de espaços livres - conceitos, conflitos e paisagens. Em processo de edição pela FAUUSP, contém os 17 textos produzidos para o V Colóquio QUAPÁ-SEL, realizado na FAUUSP em outubro de 2010, que congregou mais de 50 pesquisadores.

Livro 3 - Os sistemas de espaços livres e a constituição da esfera pública contemporânea no Brasil. Texto referência, dividido em cinco capítulos, objetiva mostrar as conclusões da equipe de pesquisadores do projeto derivadas dos estudos 
efetuados no período. Este livro não abrange todo o material coletado e nem coloca todo o material gráfico elaborado, é sim a síntese do que discutimos e analisamos nestes anos do Projeto.

\section{DOS PONTOS DE REFLEXÃO DURANTE O PROJETO}

i. A conceituação dos espaços livres;

ii. A compreensão das bases técnicas e conceituais dos gestores e as iniciativas de qualificação dos espaços livres - durante o período foram feitas visitas e contatos com entidades gestoras dos espaços livres nas cidades em estudo, ao menos uma por cidade, de modo a avaliar seu papel na constituição dos sistemas e detectar dificuldades, sucessos e conflitos;

iii. $\bigcirc$ estudo da estruturação recente dos sistemas de espaços livres em centros urbanos importantes do país;

iv. A análise das relações existentes entre os espaços livres públicos e privados;

v. O conhecimento dos órgãos de planejamento dos sistemas de espaços livres vigentes no país. $\bigcirc$ resultado é bastante satisfatório, pois os investimentos em espaços livres são significativos e crescentes, por outro lado, as estruturas de gestão em geral estão bastante aquém dos investimentos feitos, não conseguindo garantir a manutenção satisfatória de grande parte dos espaços dos sistemas;

vi. A contribuição dos diversos sistemas de espaços livres para a constituição da esfera pública - a discussão do conceito esfera pública e sua relação com alguns dos tipos de espaços públicos;

vii. A complementação do banco de dados do laboratório QUAPÁ - durante o período criamos 100 mapas temáticos principais, especialmente concebidos e desenvolvidos para a pesquisa e a partir deles foram gerados já mais 150 mapas de detalhamento. Foram ainda feitas fotos dos espaços livres em estudo, além de cerca de 25.000 fotos aéreas que foram incorporadas ao banco de imagens do laboratório. Todo este material está disponível para consulta no Laboratório QUAPÁ e nos núcleos que constituem a rede de pesquisa QUAPÁ-SEL. Este acervo tem servido de apoio para diversas outras pesquisas, textos, trabalhos de alunos, aulas de graduação e pós-graduação, do LAB-QUAPÁ, LAP e LAB-HAB da FAUUSP. Inclusive para o livro Produzir casas ou construir cidades, recentemente elaborado pelo LAB-HAB;

viii. Revisão dos modelos e conceitos que direcionam o pensamento gerador de planos relacionados aos espaços livres.

\section{DOS MÉTODOS PROPOSTOS - COLÓQUIOS E OFICINAS}

modelo foi aprimorado e sua formatação final já foi inclusive aplicada por outros grupos de pesquisa em Vitória, Florianópolis e Rio de Janeiro.

Organizamos pelo Brasil 23 oficinas, uma por cidade pesquisada e duas em São Paulo. Será feita neste ano de 2011 a oficina em Porto Alegre, complementando em continuidade os trabalhos da pesquisa. 
Os colóquios foram criados pela necessidade de congregar os pesquisadores da rede em um mesmo lugar, de modo a se entabular discussão ampla sobre as pesquisas em andamento e estabelecer padronização conceitual e metodológica. Consistem na apresentação de trabalhos e atividades coletivos de ateliê, nos quais são analisados e apresentados mapas temáticos e discutidos conceitos e finalmente apresentação coletiva dos debates. Os colóquios se mostraram eficientes no processo de avaliação do desenvolvimento dos trabalhos e hoje constituem eventos científicos anuais do grupo e da rede de pesquisa, já tendo sido feitas cinco edições, três em São Paulo, uma em Curitiba e outra no Rio de Janeiro.

\section{DOS MAPAS TEMÁTICOS}

Foram criados quatro tipos de mapas temáticos, dois referentes aos espaços livres e a verticalização intraquadra, executados em ARCGIS, e os demais derivados de mapas síntese produzidos nas oficinas, analisando elementos da paisagem, mancha urbana e características dos espaços livres públicos no sistema de cada cidade, executados em Adobe llustrator.

Foram elaborados na totalidade mais de 200 mapas temáticos (de verticalização e espaços livres por quadra das 40 cidades estudadas e das regiões metropolitanas de Campinas, São Paulo e Vitória).

Em função do envolvimento com essas atividades, alguns estudos foram feitos experimentalmente, como o estudo gráfico da legislação de loteamentos e a simulação da legislação de zoneamento as cidades, foram os casos de Maceió, São Paulo, Campinas, Belém do Pará e Curitiba.

O Laboratório QUAPÁ é o responsável pela produção apresentada e pela continuidade dos trabalhos aqui propostos e que estão programados para os próximos cinco anos com novos enfoques e objetivos. $O$ grupo se constituiu dos seguintes pesquisadores, além de seus coordenadores nacionais: Dra. Vanderli Custódio (IEB/USP), Dr. Fábio Mariz Gonçalves (FAUUSP), Arqła. Fany Galender (pesquisadora do LAB-QUAPÁ e Prefeitura Municipal de São Paulo), Dr. Rogério Akamine (UNINOVE), Dr. Jonathas M. P. Silva (PUC-Campinas), Dra. Ana Cecília de Arruda Campos (LAB-QUAPÁ), Dra. Helena Napoleon Degreas (FIAM FAAM) e com a colaboração do Ms. Roberto Vignola Jr., Paisagista (LAB - QUAPÁ/Prefeitura Municipal de São Paulo) e do Dr. Manuel Lemes (PUC-Campinas).

A continuidade entre os projetos QUAPÁ-SEL e QUAPÁ-SEL II se dá pela perspectiva do entendimento da importância dos sistemas de espaços livres nas cidades brasileiras e pela necessidade de aprofundamento das questões já levantadas. No primeiro projeto temático buscou-se observar as relações entre tais sistemas, sejam públicos ou privados, e a esfera pública contemporânea brasileira. Durante todo o seu período nos aproximamos e tangenciamos questões ligadas à forma urbana, tanto nos estudos espaciais de legislação, como no entendimento das quadras e seus espaços livres e ainda da paisagem das cidades em questão. Neste projeto, a ênfase está nas relações 
de produção e apropriação que se estabelecem entre os sistemas de espaços livres e a constituição da forma urbana brasileira na atualidade.

A forma urbana se constitui, enquanto sistema, pela somatória e relação entre os espaços livres e edificados, públicos e privados, legais e ilegais, acolhedores ou excludentes. É produto social e, ao mesmo tempo, condição para o processo social (LEFĖBVRE, 1974). Vários autores vêm se debruçando, no Brasil, sobre os estudos morfológicos na Área de Arquitetura e Urbanismo', mas ainda de modo isolado e fragmentado. Mas, apesar deste avanço, o que se tem nesta primeira década do século é a fragmentação de estudos (PEREIRA COSTA, 2006, 2007 e 2008; TÂNGARI, 2007, por exemplo) e a inexistência no Brasil de novas investigações mais gerais sobre a questão que foi, por motivos diversos, relegada a um segundo plano. Algumas publicações do período detêm-se a aspectos funcionais do desenho urbano, constituindo-se em manuais práticos².

Existem exceções importantes e, recentemente, o único momento de convergência nacional foi o ISUF - International Seminar of Urban Form, realizado em 2007 sob os auspícios da UFMG e de seu grupo de pesquisadores, encabeçado por Stael Alvarenga e Marieta Maciel, e o livro organizado por Vicente Del Rio e publicado nos Estados Unidos denominado Contemporary Urbanism in Brazil - Beyond Brasília.

Pretende-se, nesta pesquisa, a (re)união e debate com maior número de pesquisadores sobre o assunto, de modo que se tenha visão atualizada, crítica e abrangente do estado da arte na realidade brasileira. Esta pesquisa pretende contribuir neste debate, a partir do viés do sistema de espaços livres, entendendo como elemento ainda fundamental da vida pública ${ }^{3}$.

Imagina-se, pois, congregar conhecimento e esforços de modo ao entendimento dos padrões tipológicos dos tecidos urbanos brasileiros e de seu papel na constituição dos sistemas de espaços livres e, de modo indireto, na constituição da esfera pública nestes espaços.

A forma não tem existência autônoma ${ }^{4}$. Esta é a primeira assertiva a se fazer quando se propõe investigação sobre qualquer tipo de forma. $O$ reconhecimento da importância da forma no processo socioespacial significa compreendê-la como categoria analítica do espaço. Não se trata, portanto, de "formalismo" versus "funcionalismo", versus "estruturalismo", mas de compreensão do movimento dialético, que se estabelece entre as categorias analíticas do espaço. Neste sentido, refletindo sobre a dinâmica da totalidade espacial, Santos (1985, p. 49-59) propõe a ideia da dialética entre forma, função, estrutura e processo: a forma desempenha a função ditada pelo presente, ou seja, pelas urgências da estrutura social do presente, que em movimento compreende a ideia de processo. O avanço analítico do autor levou-o a elaboração do conceito síntese de forma-conteúdo que uniria "[...] o processo e o resultado, a função e a forma, o passado e o futuro, o objeto e o sujeito, o natural e o social." (SANTOS, 2002 , p.103.) Sistematização que reforça a assertiva inicial: a forma não é autônoma.

O espaço livre é inerente à forma urbana. A cidade brasileira deste início de século tem configuração bastante distante daquela existente nos anos 1980, quando estiveram 
no auge os estudos da forma urbana. A forma é derivada tanto do crescimento em extensão e população, como pela introdução de novos modelos urbanísticos como: os loteamentos fechados e condomínios de grande porte; as áreas industriais ao longo de estradas e afastadas dos grandes centros; as vastas áreas de habitações precárias imersas no tecido urbano; os parques lineares e as grandes orlas tratadas; as novas áreas centrais e a verticalização extensiva que extrapola as antigas áreas verticalizadas e se espraia por amplas áreas da malha urbana.

Com certeza os fatos mais importantes das duas últimas décadas são o aumento exponencial e constante da frota de veículos automotores, a ampliação das redes de estradas e a adaptação cada vez maior das redes viárias urbanas ao automóvel, ao ônibus e ao caminhão, com os inerentes conflitos criados.

Nota-se o crescimento da demanda pela arborização e pela inserção da vegetação na cidade, ao mesmo tempo em que se percebe que nem nos bairros de alta renda ela é privilegiada. Mesmo a introdução na legislação, na década de 1990, da figura da APP5 urbana pouco melhorou este estado de coisas, criando estoques de terras públicas, que um dia, talvez, serão tratadas e utilizadas pela população. A arborização de rua, assim como a vegetação de porte, como matas, bosques, etc., são elementos estruturadores da forma e da paisagem urbana do mesmo modo que as construções e o suporte físico, mas tal fato não é considerado importante no cotidiano urbano.

Por outro lado, sua existência como elemento de conservação de dinâmicas ecológicas é apregoada por ambientalistas, sendo inegável a importância na constituição de microclimas nas áreas de drenagem urbana de um país tropical como o Brasil.

Se a forma da cidade é importante em termos da definição e qualificação das áreas de habitação, trabalho, lazer e proteção de recursos ambientais, por outro lado, tem sido desqualificada como objeto de análise, do mesmo modo que o são os espaços livres em geral. Exemplo disto é a ampla negligência, por parte do Poder Público e da população, na maioria das cidades brasileiras na constituição da rua, principal espaço livre urbano, com calçadas geralmente subdimensionadas e leito carroçável nem sempre apto à circulação adequada.

Consideram-se os espaços livres como uma das principais infraestruturas urbanas, pois neles e por eles grande parte da vida cotidiana tem lugar, assim como são um dos principais palcos dos conflitos e acordos da sociedade. O espaço público, a rua em especial, tem papel estruturador na constituição da forma urbana, pois reflete as formas de mobilidade, acessibilidade e circulação, parcelamento e propriedade da terra urbana.

O estudo da forma urbana não é considerado importante apenas para a definição e entendimento de padrões estéticos, mas sim pelo papel de contenedora da vida social, de estruturadora dos sistemas de espaços livres e de interlocutora direta com as dinâmicas ecológicas preexistentes e com o sítio de cada localidade.

Entende-se que existem formas típicas da cidade contemporânea brasileira, amálgama de influências do estrangeiro associadas a criações locais, cuja existência está 
atrelada à lógica de produção do mercado e do Estado. $O$ entendimento destas nos permitirá elaborar crítica consistente do estado da arte e, portanto, o estabelecimento de métodos de análise e de critérios para futuras ações.

A forma da cidade brasileira está vinculada aos processos de produção, às formas de propriedade e parcelamento, aos padrões culturais, às desigualdades sociais e às características do suporte biofísico e climático. Mesmo no confronto de cidades de porte similar, pode-se afirmar a existência de especificidades locais, revelando que as formas urbanas não são mera decorrência das lógicas econômicas mais estruturais.

Por exemplo, favelas, parques e verticalização, existem em todas as grandes cidades, mas sua constituição formal e espaços livres variam de acordo com a constituição socioeconômica da comunidade local, com as normas edilícias e com as práticas culturais específicas, podendo existir inclusive variações entre diferentes partes da mesma metrópole.

Pensa-se, apesar da diversidade, pela experiência acumulada, que é possível estabelecer e detectar lógicas de produção, padrões e tipos específicos de tecido urbano, de sistemas de espaço livres (conforme estabelecido na primeira fase da pesquisa - QUAPÁ-SEL I) e padrões de parcelamento que mostrem a realidade da paisagem urbana nacional.

\section{CONSIDERAÇÕES SOBRE FORMA URBANA}

A forma espacial ${ }^{6}$ é entendida como resultado e fator social, pois é oriunda do trabalho dos homens organizados em sociedade, é prenhe de intencionalidades e simbolismos; não é mera coisa, oriunda da natureza (SANTOS, 2002, p. 64.). A forma espacial pode ser edifício, rua, praça, bairro, cidade, conjunto de cidades, etc..

A forma pode conter outras formas, a cidade contém inúmeras formas e está contida em outras tantas. Tratando de espaço, não estamos falando de simples geometria espacial, de mero espacialismo e sim de sistema complexo (MORIN, 2008), que compreende tanto a complexidade funcional (relativa à função que a forma desempenha) quanto a complexidade estrutural (relativa ao conjunto de informações, de elementos que a compõe) (MOLES7, 1971, p. 78, apud SANTOS, 2002, p. 69). Tão mais complexa estruturalmente é a forma, quanto mais apta estaria a dar respostas rápidas e eficazes. Pesquisa-se, portanto, como as cidades brasileiras (formas espaciais que são) estariam aptas a dar quais tipos de respostas? A quem?

O Movimento Moderno na arquitetura e urbanismo consolidou o paradigma "forma-função", entretanto, houve diferentes correntes teóricas e formas de produção que se envolveram com a construção da forma e da paisagem urbana.

No Pós-Guerra, em fins da década de 1940, já se estabelecem críticas à cidade dispersa pelo zoneamento funcional, buscando a re-centralização onde possa se manifestar o sentido da comunidade (ARANTES, 2000). No Brasil, especificamente, apesar das diversas experiências de desenho urbano (Serra do Navio, Brasília), o planejamento se distancia da prática de projeto, restringindo-se à elaboração de 
planos e seus respectivos índices. As formas geradas são resultantes de legislação específica, aplicadas por diversos agentes ou decorrentes da atuação informal de seus habitantes. De qualquer modo, o desenho intencional de trechos urbanos ficou restrito às ações pontuais.

Os aspectos funcionais, quantitativos, qualitativos, ambientais, figurativos ou estéticos da forma urbana, estão associados e assim devem ser considerados no processo de observação da paisagem, mas, também, conforme Hepner $\left(2010\right.$, p.28) ${ }^{8}$, "[...] a interpretação desses aspectos depende [...] principalmente do contexto socioeconômico e cultural, ou seja, da 'dupla morfologia' existente na cidade". Trata-se, cabe reiterar, da consideração da forma urbana como processo.

Os aspectos propositivos e práticos da morfologia urbana advêm do fato de buscar soluções para os problemas urbanos considerando as características quantitativas, de organização funcional, e as qualitativo-estéticas. Para tanto, há de considerar inúmeras variáveis como: o sítio (indissociável da produção das formas urbanas); os limites espaciais da mancha urbana; os vários elementos das escalas da rua a da cidade; o tipo de pavimento; os tipos de edifícios; os cheios e os vazios da cidade; etc. Todas as variáveis referentes aos espaços livres urbanos.

A investigação sobre a forma espacial urbana pelo urbanismo passa pela consideração do Desenho Urbano, como disciplina que tradicionalmente a estuda. Tal campo disciplinar ressurge com autonomia, formalmente reconhecido em meados do século XX, decorrente das críticas ao urbanismo moderno que levam a novas abordagens conceituais sobre a cidade. Nestas últimas décadas são muitas as contribuições teóricas e instrumentais para o Desenho Urbano, constituindo diversas vertentes e áreas de concentração que não apenas as da arquitetura e urbanismo.

Quatro abordagens do Desenho Urbano, relacionado à forma urbana, podem ser identificadas (HEPNER, 2010): metodológica (DEL RIO)9, epistemológica (MOUDON) $)^{10}$; a pragmática (CARMONA et al. $)^{11}$; e crítica (CUTHBERT) ${ }^{12}$.

$\mathrm{Na}$ "abordagem metodológica", o Desenho Urbano é vinculado ao processo de planejamento e, consequentemente, às políticas públicas. Estrutura-se a partir do trabalho do psicólogo ambiental David Canter $(1977)^{13}$, no qual o espaço é percebido e interpretado pelo homem segundo três esferas distintas: "Os atributos físicos dos espaços, as atividades ou usos que lhe são atribuídos, e as concepções ou imagens geradas sobre estes espaços." (HEPNER, 2010, p.51) Partindo destas esferas, Del Rio estabelece quatro categorias de análise do espaço urbano: i) morfologia urbana ou atributos físicos; ii) comportamento ambiental ou as atividades e usos que estabelecem a relação entre o homem e o espaço urbano; iii) análise visual; e, iv) percepção ambiental. Embora a formulação destas categorias não seja original de Del Rio, a importância de seu trabalho está na estruturação de metodologia que permite incorporar o desenho ou projeto urbano - como leitura da forma urbana - ao planejamento urbano, isso considerando as particularidades das cidades brasileiras.

A "abordagem epistemológica" busca identificar, reunir e sistematizar todas as áreas de concentração pertinentes ao desenho da forma urbana, adotando visão 
mais ampla possível, ao invés de convicções, concepções e paradigmas individuais. Moudon define nove áreas de concentração dos estudos: i) história urbana: analisa a estrutura e forma das cidades e seus processos de transformação; as principais obras são de Mumford (1961)14, Benevolo (1980)15, Morris (1979)16, Kostof (1991)17; ii) estudos pitorescos: enfocam os atributos visuais das cidades e a paisagem urbana; a principal obra é a de Cullen (1961)18, além dos trabalhos pioneiros de Sitte (1889) ${ }^{19}$ e Unwin $(1909)^{20}$; iii) estudos imagéticos: tratam dos processos cognitivos relacionados com a vivência e reconhecimento do espaço urbano; a principal obra é a de Lynch $(1960)^{21}$, incluindo ainda Ashihara (1983) ${ }^{22}$; iv) estudos ambiente-comportamento: relacionados à psicologia e sociologia, avalia como o comportamento humano e as relações sociais são afetados pelo espaço segundo sua configuração formal, funcional e figurativa, enquanto possibilismo e probabilismo ambiental, refutando o determinismo ambiental; as principais obras são de Lang (1987)23, Rapoport (1977) ${ }^{24}$ e Gehl (1987)25; v) estudos do lugar: com enfoque fenomenológico, baseado na experiência individual, segundo aspectos emocionais, detêm-se nos ambientes vernaculares e manifestações culturais; a principal obra é de Norberg-Schulz (1980) ${ }^{26}$, incluindo ainda Whyte (1988) ${ }^{27}$ e Lynch $(1981)^{28}$; vi) estudos da cultura material: com enfoque antropológico, concentra-se no estudo dos objetos (de utensílios ao ambiente construído) para entender, a partir deles, a sociedade e a cultura que os produziv; a principal obra é a de Venturi (1977) ${ }^{29}$, mas cabe também citar a de Jackson $(1980)^{30}$; vii) estudos tipo-morfológicos: analisa a forma urbana segundo seus atributos físicos, os sistemas de relações espaciais e volumétricas que a estruturam, o processo evolutivo e como é gerada pela sociedade; as principais obras são as de Rossi (1966) $)^{31}$, Aymonino (1975) ${ }^{32}$ e Krier (1979) ${ }^{33}$; viii) estudos espaçomorfológicos: concentram-se nas características fundamentais da geometria urbana, elencando elementos ou unidades espaciais e como estes se conjugam, gerando a forma urbana; as principais obras são as de Alexander (1971, 1977) ${ }^{34}$; Hillier \& Hanson $(1984)^{35}$ e Hillier (1996) ${ }^{36}$; ix) estudos natural-ecológicos: entendem a ecologia urbana como componente fundamental no desenho urbano; as principais obras são as de McHarg (1969) ${ }^{37}$, Spirn (1984) ${ }^{38}$ e Hough (1995) ${ }^{39}$.

A "abordagem pragmática" busca orientar o entendimento e a atuação de profissionais ligados ao desenho urbano através de amplas contribuições teóricas e práticas, ainda que partindo de experiências norte-americanas e britânicas e possibilita a transposição da teoria à prática através de três aspectos: i) o contexto de atuação: contexto local (particularidades incluindo características ambientais, climáticas, suporte físico, disponibilidade de recursos e tecnologia, relações sociais, necessidades materiais, cultura da população), contexto global (como o ambiente urbano local se relaciona com o meio ambiente global, ou "sustentabilidade" ambiental), contexto do mercado (formas de produção de espaço urbano, centrado principalmente na iniciativa privada), contexto regulatório (como o setor público regula e fiscaliza a estrutura legal que orienta a ação privada, ou políticas públicas); ii) as dimensões da intervenção: é o desenho urbano manifesto e percebido nos aspectos da realidade, através de seis dimensões - morfológica, perceptual, social, visual, funcional e temporal; iii) as formas 
de implementação: processo de transposição do desenho urbano à realidade, que sempre deriva das intenções originais devido às alterações de contexto e incongruências entre as diferentes dimensões do próprio desenho urbano. São três os processos, todos interligados - processo de promoção (construção e adaptação do ambiente urbano para atender finalidades diversas, envolvendo diferentes agentes), processo de controle (papel desempenhado pelo setor público e suas ações regulatórias com reflexos na qualidade do ambiente urbano) e processo de comunicação (como concepções e projetos de desenhos urbanos são apresentados, discutidos e encaminhados pelos diferentes agentes, na esfera pública e privada).

A "abordagem crítica" define o desenho urbano como processo pelo qual a sociedade dá forma ao espaço que habita, atribuindo ao ambiente construído significados e valores. Sua proposta relaciona os diversos fatores envolvidos nos planos: social, econômico, político, cultural e ideológico, buscando compreender como afetam a produção do espaço urbano de maneira ainda pouco esclarecida. São dez os eixos temáticos, integrados de acordo com perspectiva crítica proposta por Cuthbert: teoria (desenho urbano como construção teórica); história (o que se pode aprender da história para o desenho urbano); filosofia (sistemas de significados informados pelo processo urbano); política (sistemas de valores e compromissos envolvidos no desenho das cidades); cultura (como sociedade e cultura dão origem à forma urbana); gênero (como este influencia o desenho urbano); ambiente (implicações do mundo natural); estética (reino dos sentidos em relação à forma urbana); tipologias (formas organizacionais identificadas no desenho das cidades); pragmática (o que os desenhadores urbanos devem conhecer).

Essas quatro abordagens, bem agrupadas por Hepner (2010), apresentam o estado da arte do estudo tradicional da forma no urbanismo (pela disciplina de desenho urbano). Nossa ênfase, entretanto, é da produção e apropriação da forma da cidade a partir dos espaços livres urbanos no Brasil contemporâneo, que incorpora os procedimentos das abordagens "pragmática" e "crítica".

\section{REFERÊNCIAS}

Contextualizando-se nas estruturas ideológicas do urbanismo mundial, a década de 1970 marcou profundas mudanças no ensino e na prática do urbanismo: as discussões até então pautadas nos referenciais técnicos (questões construtivas e de ordem sanitária) e estéticos passaram a enfocar os processos e os problemas sociais urbanos. Em comum e permanente, as duas propostas não tratam das questões vinculadas à forma urbana, à organização espacial e social. De um lado, as questões que tratam das normas de ordenação das estruturas espaciais urbanas que se mostram incapazes de oferecer minimamente níveis de interação social. De outro, a aparente "desordem" da geometria irregular, da sobreposição de formas, usos e atividades não previstos nos instrumentos de análise do planejamento e do desenho urbano tradicionais.

Os "desenhadores do espaço urbano" trataram de, nas palavras de Nelson (1984), 
quebrar suas lapiseiras jogando-as fora e, deixando de falar a linguagem própria, aderiram ao mau "sociologês", "economês", "geografês"... Afastando-se do problema e da razão de ser da forma do espaço e da sociedade materializada nas formas urbanas. Negando-se a desenhar as ruas, as esquinas e as infraestruturas.

Daí a necessária retomada das discussões sobre a forma urbana. Investigandose as origens, as razões e os comportamentos dos indivíduos nas formas sejam elas reguladas ou controladas pelo Estado, por meio de seus índices e planos, ou, sejam elas "autônomas", produzidas sem a intervenção estatal.

A década de 1990 foi marcada no Brasil por discussões que apontavam para o recuo do espaço público na cultura urbana contemporânea. Frúgoli Jr (1995) evidencia a deterioração dos espaços públicos e o surgimento dos espaços privatizados palco das novas relações sociais na vida pública (malls, condomínios fechados, centros empresariais, entre outros), além de procedimentos privatizantes que incorporam o espaço público com destinação "socioambiental". Na mesma linha, Regina Meyer considera que atividades tipicamente urbanas foram transferidas para novos espaços, produzidos segundo novos valores e a partir de novos instrumentos urbanísticos como ruas e praças abrigadas, protegidas a partir de novas concepções de cidade e de vida urbana.

Os anos 1990 se caracterizaram ainda por motivações teóricas e político-partidárias da geração engajada na luta pela reforma urbana e que objetivavam o desmanche dos dogmas e fórmulas do "bom planejamento", a partir da associação com lideranças comprometidas com a transformação das cidades brasileiras. Dentre elas, destaca-se Raquel Rolnik (1997) que busca a "ordem urbanística", a partir da formulação de pacto territorial entre alguns setores e mercado, que preside o desenvolvimento das cidades há décadas. Pelo mesmo caminho da militância em movimentos populares urbanos, Ermínia Maricato aborda o apartheid urbano, resultado da articulação contraditória entre a norma e a infração no espaço da metrópole brasileira associado à sociedade de classes, cujas relações encontram-se calcadas no favor, no privilégio e na arbitrariedade que, para ela, negam a universalidade dos direitos (embora previstos na norma legal) ou a negação da cidadania e da dignidade, confundindo a coisa pública e negócios privados, o governo e o Estado.

No início dos anos 2000 foi promulgada na forma de Lei n. 10.257, de 10 de julho de 2001, conhecida por Estatuto da Cidade, que estabeleceu normas de ordem pública e interesse social que regulam o uso da propriedade urbana em prol do bem coletivo, da segurança e do bem-estar dos cidadãos, bem como do equilíbrio ambiental. Estabelecendo a política urbana que tem por objetivo ordenar o pleno desenvolvimento das funções sociais da cidade e da propriedade urbana, criando instrumentos urbanísticos que a viabilizem. $\bigcirc$ Estatuto foi o resultado de série de críticas dirigidas aos planos diretores e seus zoneamentos. A essa situação, seus críticos buscaram alternativas à visão tecnocrática dos planos e do processo de elaboração das estratégias de regulação urbanística tratando a cidade como objeto puramente técnico. Para eles, o planejamento apenas estabelece padrões 
satisfatórios (pelas regulações urbanísticas), ignorando conflitos, desigualdade de condições de renda e sua influência sobre o funcionamento dos mercados urbanos, excluindo a população do uso e fruição da cidade. Recentes, os instrumentos de indução para o desenvolvimento urbano presentes no Art. $4^{\circ}$, merecem destaque, pois tratam de temas vinculados ao planejamento tais como parcelamentos, distribuições, outorgas, desapropriações, operações urbanas, entre outros. Novamente, não se faz nenhuma menção à forma urbana.

Na FAUUSP, a partir dos anos de 1970, começaram a se desenvolver estudos e pesquisas referentes à paisagem urbana, nas quais espaços livres e forma urbana estão intimamente associados. Estes trabalhos iniciados primeiramente com a Dra. Miranda Magnoli foram continuados pelo Dr. Silvio Soares Macedo, que adotou este binômio como referência para seus estudos e pesquisas, assim como de seus orientandos. Nos anos de 1980 as preocupações foram somadas as do grupo de desenho urbano de Brasília, para cujos seminários foram preparados textos e artigos sobre o assunto.

Na década de 1990, com a implantação do Laboratório da Paisagem/QUAPÁ, estes estudos foram feitos de maneira continuada, dando origem a diversas publicações e pesquisas. Em 2006, dentro do Laboratório, foi iniciado o projeto temático QUAPÁ-SEL, que objetivou estudar os sistemas de espaços livres e a esfera pública contemporânea na cidade brasileira.

Esta pesquisa produziu conjunto de conceitos sobre o assunto e seus mapas temáticos apontam para o processo de crescimento e expansão das cidades brasileiras, pautado por duas lógicas distintas. Na primeira, os elementos que geram e controlam a forma urbana são resultado direto da materialização dos índices urbanísticos criados pelas secretarias municipais de planejamento. Na segunda, despontam os princípios espaciais autoproduzidos (SANTOS, 1984), espontâneos, identificados na paisagem por meio de loteamentos clandestinos, habitações sem registro, ocupações ilegais (TURKIENICS, 1984) que se esparramam sobre o suporte físico. Uma vez criada (espontânea ou fruto de regulamentação), a forma física tende a se institucionalizar e a se reproduzir como padrão, determinando as relações e as práticas sociais nos novos espaços construídos. Paralelamente, a pesquisa gerou diferentes núcleos de pesquisa pelo país afora, totalizando, em 2011 , cerca de 15 núcleos de trabalho com tais enfoques.

No Projeto QUAPÁ-SEL I, focamos por vezes essa relação, da produção e apropriação, ao identificarmos que a cidade brasileira não tem forma padronizada, embora apresente algumas características comuns. Esse fato pode ser constatado pela forma da mancha urbana e da inserção desta no suporte físico, que configuram, somente por estes quesitos, paisagens diferentes.

Entende-se como mancha urbana a área ocupada pelas construções contidas dentro do perímetro da urbanização seja esta de portes diversos de acordo com a dimensão física: lugarejo, cidade ou metrópole. As cidades, de acordo com suas manchas urbanas, podem se apresentar de diferentes formas. São elas: 


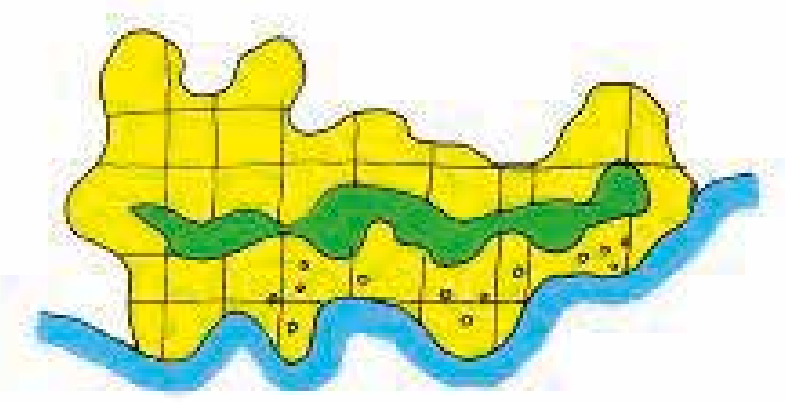

I - lineares: encontradas em meio a vales incrustados em meio a serras e terrenos de alta declividade, orlas marinhas e fluviais e ainda ao longo de estradas. Neste caso os espaços livres do entorno são de fácil acesso ou visualização.

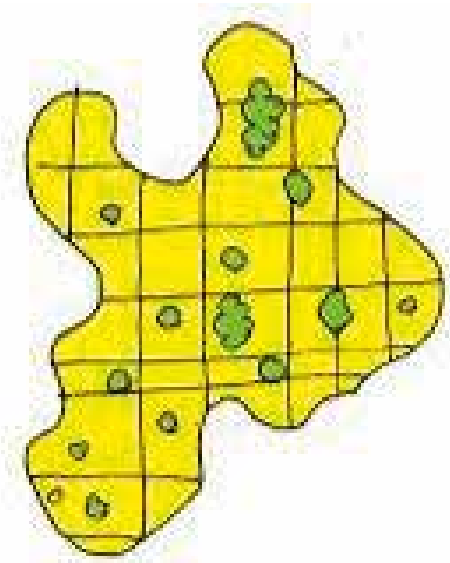

II - compactas: cidades que podem ter sua origem em qualquer das outras formas listadas, que com o crescimento vão assumindo forma compacta e contínua. No caso é mais necessária a existência de espaços livres para recreação dentro da mancha urbana.

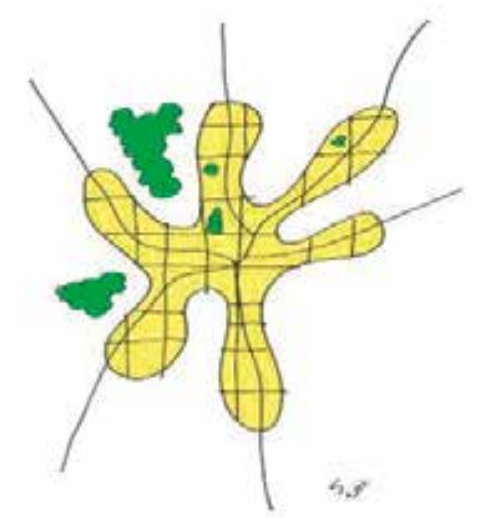

III - tentaculares: estruturadas por núcleo central, compacto, do qual irradiam braços de urbanização ao longo de eixos viários, vales ou corpos d'água. 


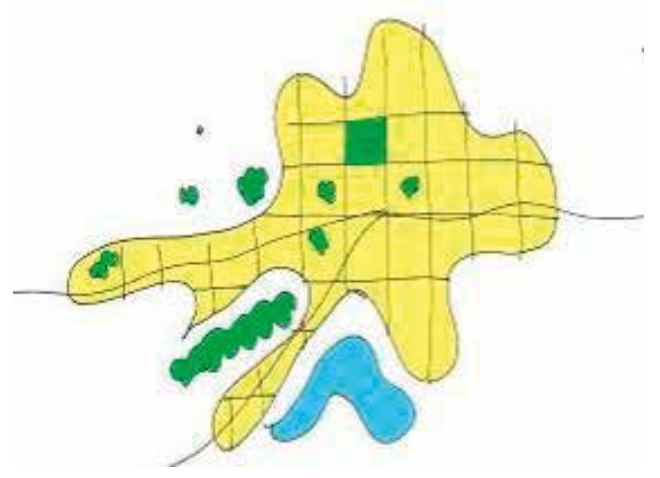

IV - mistas: o tipo mais comum.

Estas denominações são apenas referências para a classificação mais detalhada de acordo com os sistemas de espaços livres e a mancha urbana como um todo. São elas:

I - sistema de espaços livres inserido em mancha urbana compacta, caso de cidades como Belo Horizonte, Campo Grande, Maceió, Maringá, Recife, Ribeirão Preto e São Paulo.

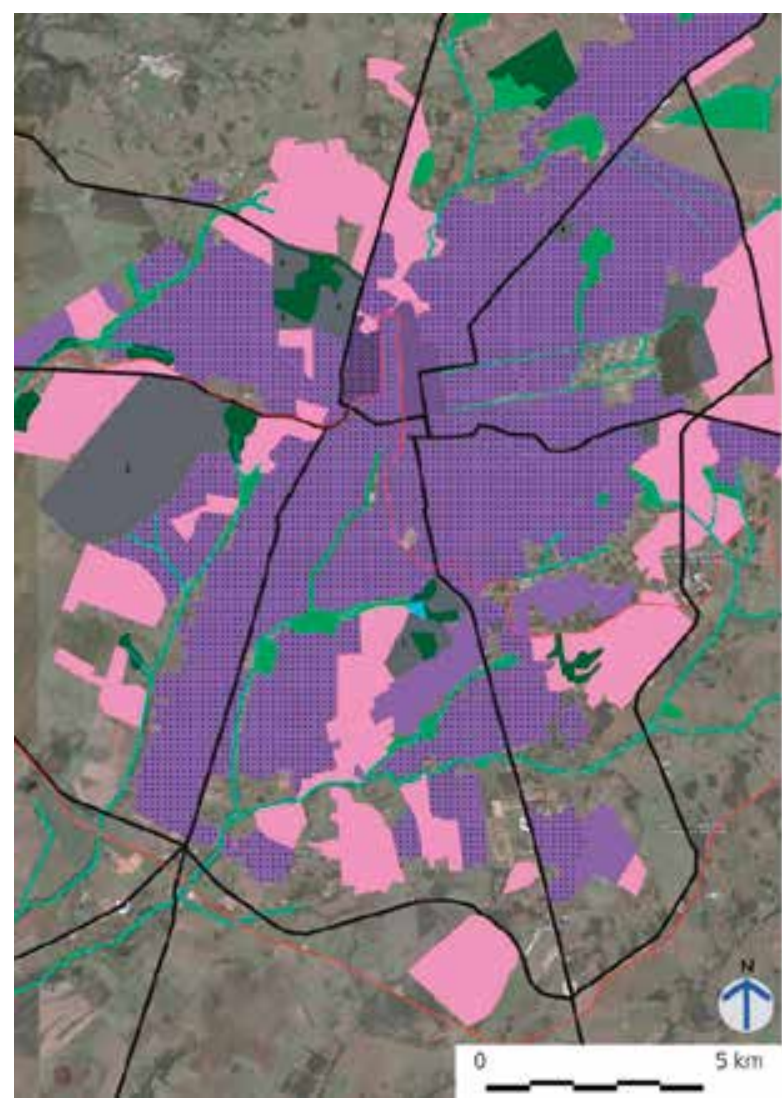

Centro

Tecido inbano tossoldado

Tecido urbana ejo conolidado

Corpos dobya

Denes, prass e ariais

Espaçus com denso cobertura vegetal

Estasos com vigetecto hetbicea elcu athusava, crm iend this a perminore Inse

Espaços com vigetescio heibácd e ou attusions, con possibilidade de ocupaço

Evaspo kine de uso especifico lonsportos grandes stadicnamentos. Stemintions, ex]

- Rodovias e vías gincipias

- Ferrovias

- Limbe Aunicipal

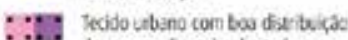
ds espacos lives implantados. formalmente (pracas parques, etc)

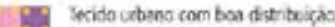
de expacos kres nfio implantados formalmente icarpos de bucteol, etd

1 Tecido ubino com atboricaçăo viäria significativa.

F. Tedido ubano con too dist bukjass de expacos lines e artorizaço viásia sinnificative.

Figura 1 - Sistemas de Espaços Livres para o Município de Campo Grande.

Fonte: Acervo QUAPÁ - Silvio Soares Macedo 
II - sistema de espaços livres inserido em mancha urbana descontínua fragmentada, dispersa em duas ou várias unidades como: Rio Branco, Santa Maria, Suzano, além do caso das metrópoles de Campinas e Brasília.

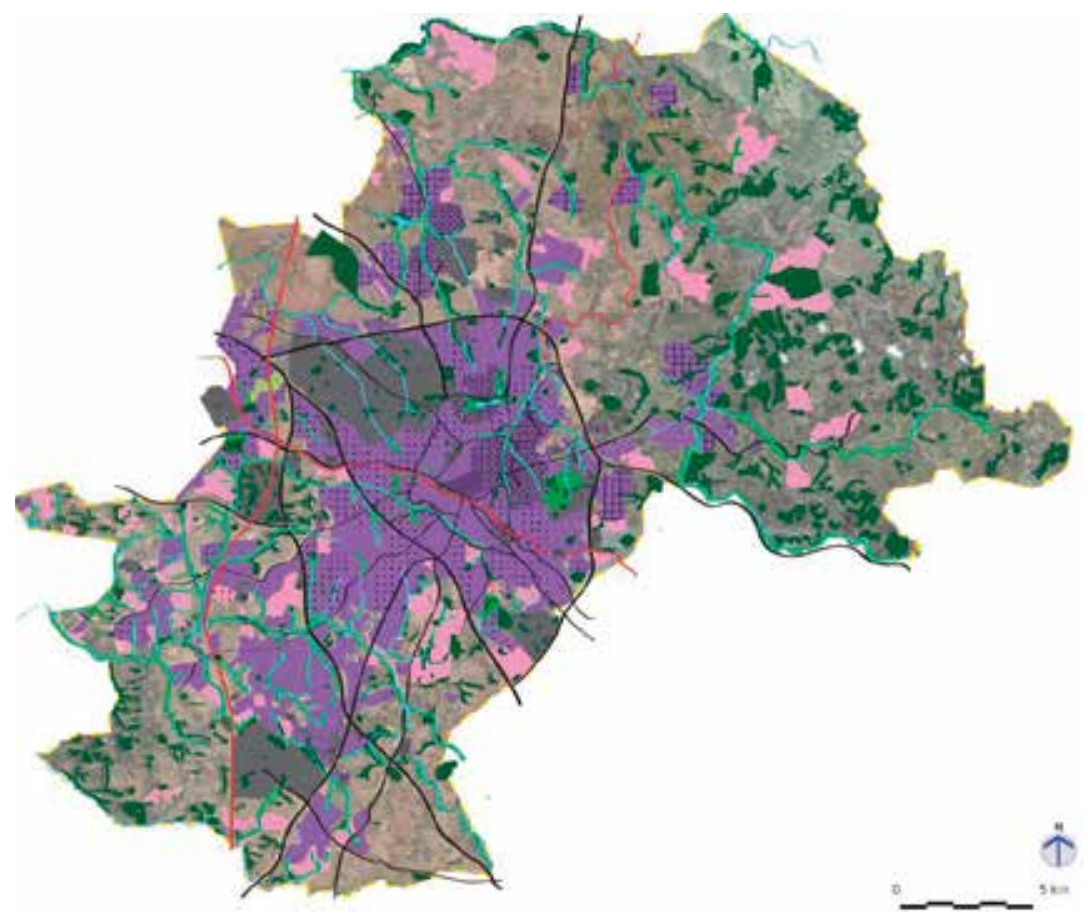

Figura 2 - Sistemas de Espaços Livres para o Município de Campinas. Fonte: Acervo QUAPÁ - Silvio Soares Macedo

III - sistema de espaços livres inserido em mancha urbana descontinuada, totalmente ou em parte, por elementos naturais de grande porte, caso do Rio de Janeiro e Florianópolis em sua porção insular, assim como Porto Alegre, Salvador, Natal e Vitória.

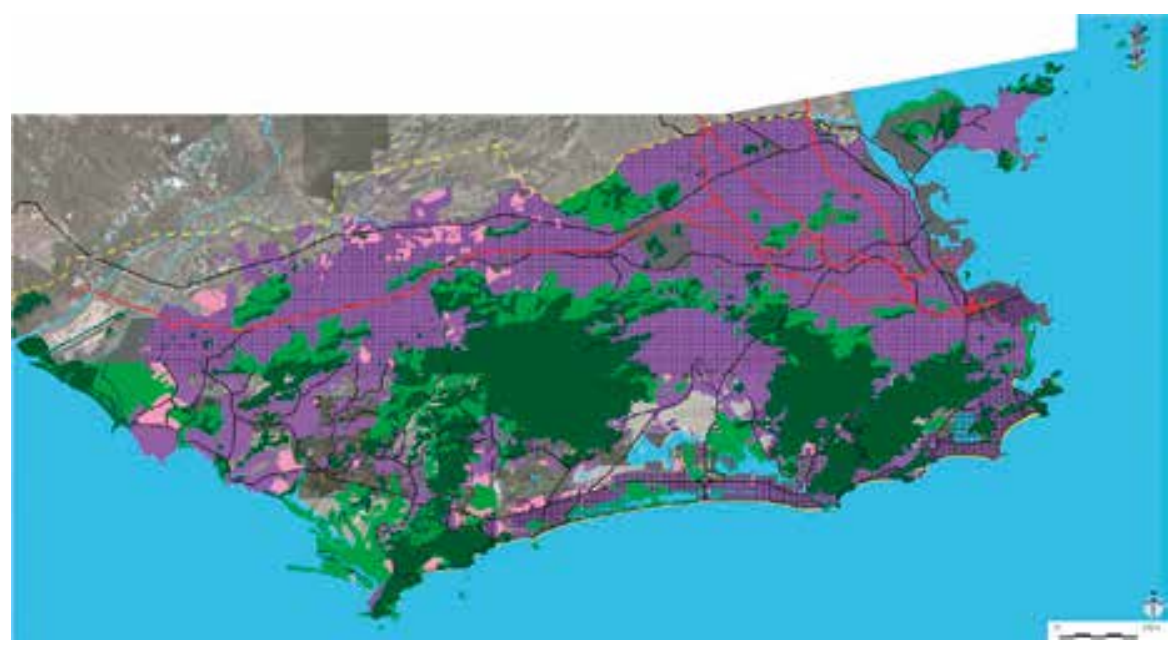

Figura 3 - Sistemas de Espaços Livres para o Município do Rio de Janeiro.

Fonte: Acervo QUAPÁ - Silvio Soares Macedo 
IV - sistema de espaços livres inserido em mancha urbana descontínua fragmentada, total ou parcialmente, por elementos naturais pulverizados, caso de Belém, Curitiba, Fortaleza, Manaus, Palmas, São Luís e Sorocaba.

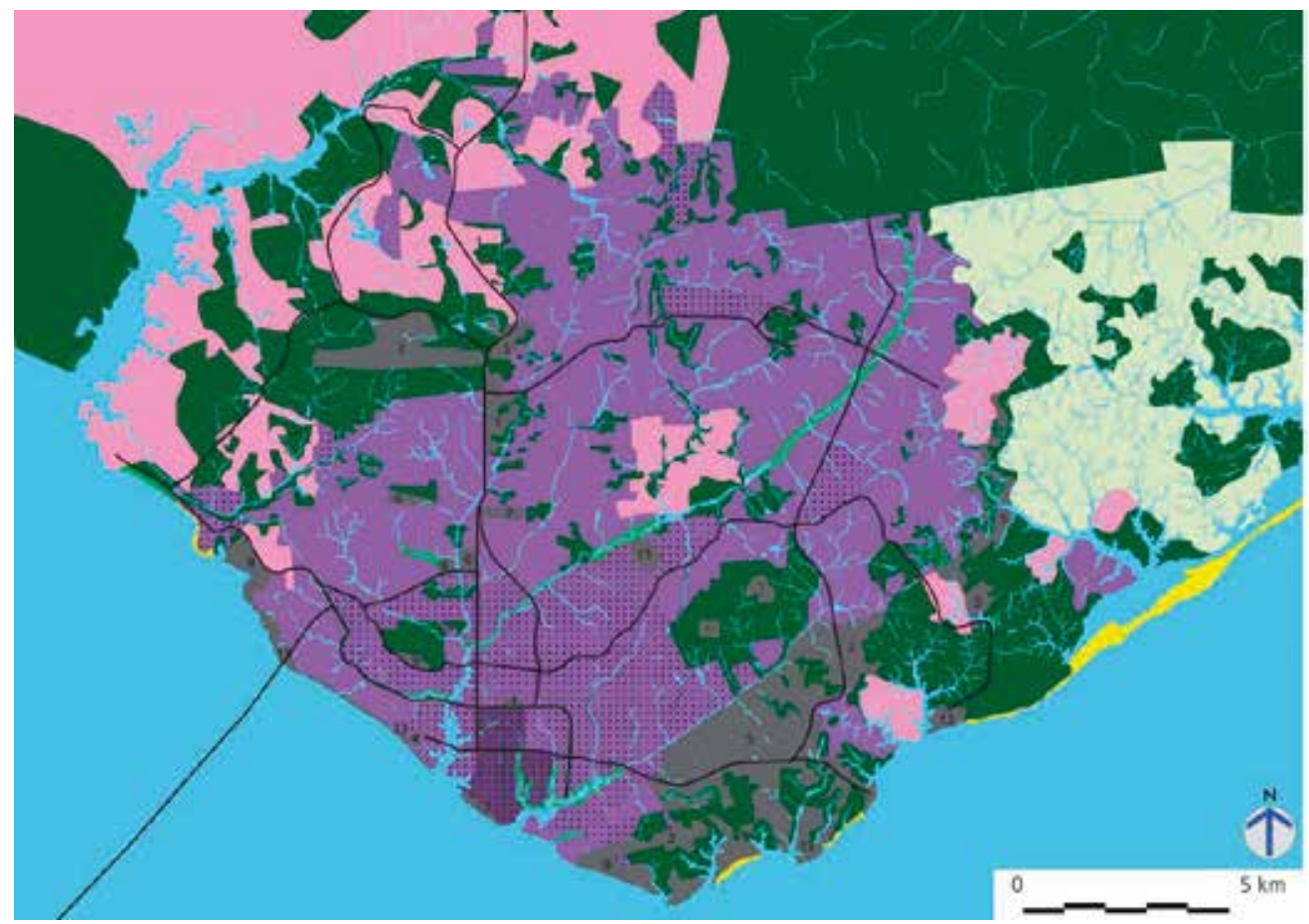

Figura 4 - Sistemas de Espaços Livres para o Município do Manaus.

Fonte: Acervo QUAPÁ - Silvio Soares Macedo

No caso de descontinuidade esta se dá pela inserção de elementos diversos do suporte físico, estuários, lagoas e dunas, ou por elementos de cobertura de porte como bosques e florestas.

Muitas dessas formas podem permanecer ao longo dos tempos devido às limitações ao crescimento, impostas pelo relevo e águas, até aquelas que se alteram rapidamente com o espraiamento urbano por áreas nas quais os obstáculos do suporte físico são modestos, expansão essa devido ao crescimento da população e das atividades econômicas.

Grandes metrópoles, como São Paulo, exigiram para seu crescimento a "superação" de barreiras físicas, como a erradicação/drenagem de extensas áreas alagadiças ao longo das calhas dos principais rios que correm pelo planalto onde se situa. $\bigcirc$ Rio de Janeiro, que teve sua área plana constantemente ampliada por aterros que ganharam terras do mar, de alagadiços e de manguezais, tendo assim a feição de sua mancha urbana alterada por meios técnicos, apesar das limitações apresentadas pelo suporte físico.

Cada mancha urbana contém conjuntos de tecidos urbanos e sistema de espaços livres particulares, que guardam entre si características similares devido às suas condições de formação e padrões culturais, urbanísticos, paisagísticos e econômicos. As figuras a 
seguir mostram os elementos constantes nos sistemas, sendo os diversos tecidos urbanos vistos como mancha amarela recortada por quadrículas, que representam o sistema viário, e são ainda recortadas por manchas verdes, que representam vegetação de porte e/ou parques, e praças e azuis, que representam corpos d'água.
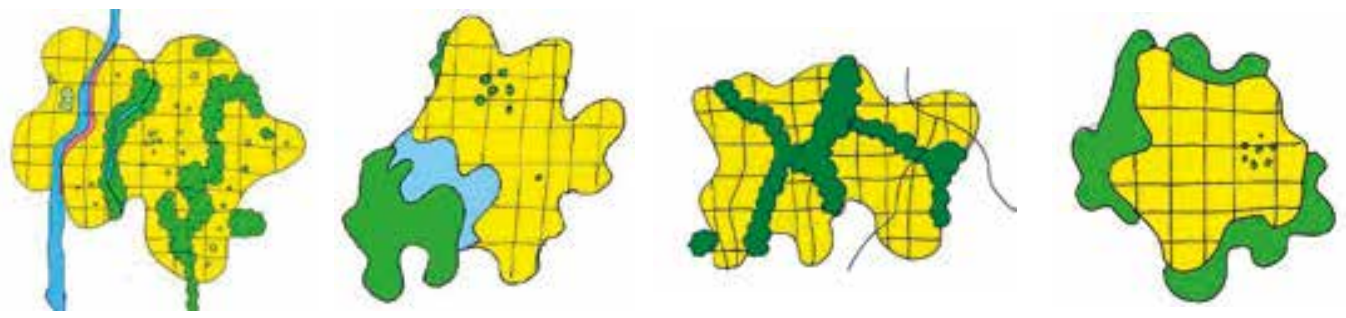

Tais figuras são simplificações, mas representam as possibilidades estruturais em que se podem apresentar as manchas urbanas das cidades. Além disso, a possibilidade de acesso de seus moradores aos espaços livres e à realização da esfera pública está diretamente vinculada à forma do perímetro da cidade e sua dimensão nos remetendo, novamente, à consideração do processo social urbano e, assim, ao aspecto não autônomo da forma.

Por outro lado, a aproximação com a forma urbana veio com a construção dos mapas temáticos que, na medida em que verificaram índices de espaços livres por quadra e de verticalização, mostraram as altas porcentagens construídas e, portanto os padrões genéricos da forma urbana vertical e horizontal, tendo-se assim bases de avaliação prévia da relação 'massas construídas' e 'espaços livres'. O cruzamento desses mapas com imagens de quadras-tipo, desenhos em escala e fotos nos mostram fragmentos de tecido e forma urbana, que são estruturados pela massa de espaços livres e edificados, que apresentam especificidades, similaridades, e demonstram as características genéricas e específicas de cada cidade estudo. A partir desse e com a criação de outros, apoiada pelo conhecimento dos agentes e atores, será possível avançar nas questões propostas.

\section{JUSTIFICATIVA}

A forma urbana é a expressão fundamental do espaço urbano, palco e resultado dos principais processos sociais - culturais, econômicos e políticos - da escala do cotidiano à escala das ações de diferentes atores hegemônicos. As relações entre os sistemas de espaços livres e a forma urbana são pouco consideradas no âmbito das políticas públicas que incidem diretamente sobre o espaço urbano.

No campo da gestão ambiental, por exemplo, pouco existe de consistente em relação à discussão da importância da cidade e em especial de seus espaços livres como elementos a serem considerados como agentes de qualidade ambiental. Como as sociedades contemporâneas são cada vez mais urbanas, pensa-se que esta é uma discussão relevante a ser considerada e pesquisada. 


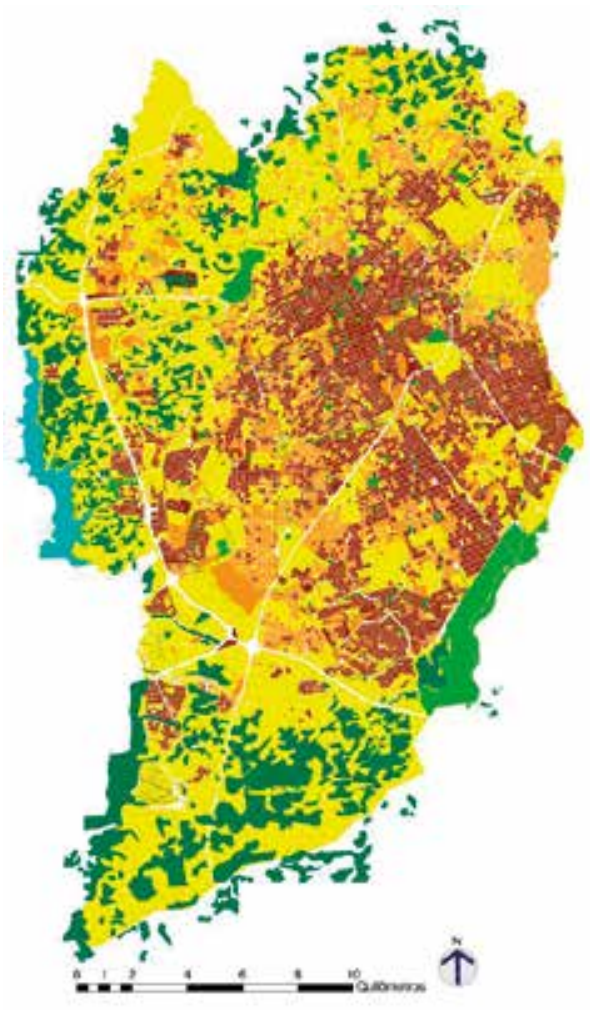

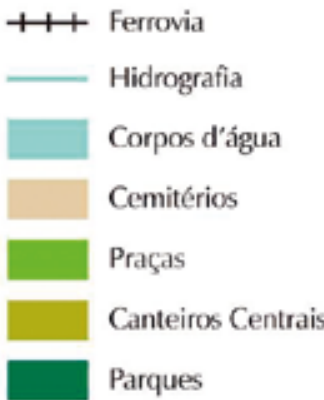

Espaços livres

De 0 a $30 \%$ de espaços livres

De $30 \%$ a $50 \%$ de espaços livres

De $50 \%$ a $100 \%$ de espaços livres.

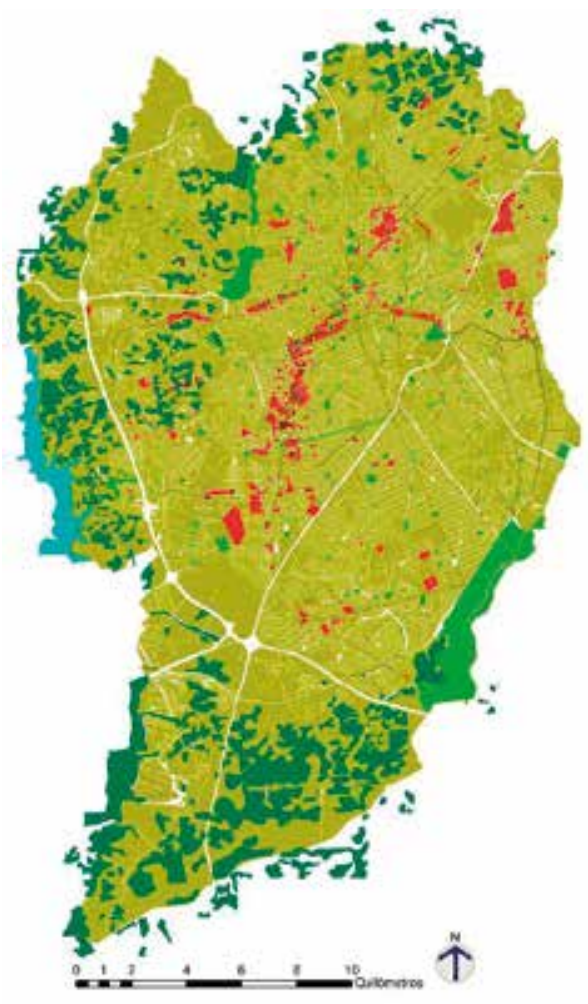

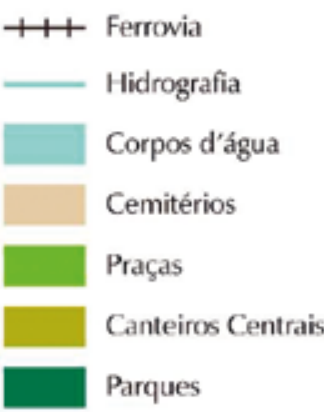

Verticalização

De 0 a $10 \%$ de verticalizaçāo
De $10 \%$ a $50 \%$ de verticalizaçấo
De $50 \%$ a $100 \%$ de verticalização:

Figuras 5 e 6 - Espaços livres intraquadra e verticalização intraquadra para o município do Manaus. Fonte: Acervo QUAPÁ - Silvio Soares Macedo 
A separação de conhecimentos sobre o espaço urbano e o ambiente urbano, embora necessária no âmbito do aprofundamento de certos objetos científicos, acarreta, por outro lado, processo que leva a fragmentação e fragilidades que dificultam o avanço de políticas públicas a respeito da qualificação de ambos.

Este Projeto Temático pretende colaborar, no âmbito acadêmico, para o ensino e a pesquisa em Paisagismo, Urbanismo, Planejamento Urbano, Geografia Urbana e Gestão Ambiental. A interação do que é construído com os elementos do clima é outro fator que pouco se discute. Como se estruturam formalmente as cidades brasileiras em território de dimensões continentais, cujos lugares sofrem a ação de diversos climas e quais são os resultados dessas interações? As sazonalidades, as circulações de ventos, entrada e saída de energia nas áreas de alta ou de baixa densidade construída, são fatores que demonstrariam as relações da influência do macroclima sobre o microclima e como estes últimos respondem àqueles, e como estes afetam o cotidiano urbano.

Por outro lado, a produção da cidade é feita pelos mais diversos agentes. Parte-se do princípio que devido à concentração de capital, população e objetos espaciais que caracterizam a cidade, é necessário qualificar a forma urbana e os espaços livres para que se possibilite o encontro público, as trocas culturais e comunicacionais (HABERMAS, 1981) e não apenas as mediadas pelo mercado.

A cidade é o espaço preferencial da acumulação capitalista e da reprodução da força de trabalho, é nela que se estabelece o preço e o valor da dessa força, das ideias e dos objetos; por outro lado, é a cidade, como forma espacial, também, o principal espaço de resistência aos processos hegemônicos, do estabelecimento da cultura e das oportunidades de exercício da cidadania. Importa, pois, compreender a produção e apropriação das formas em movimento se se deseja qualificar não apenas as formas, mas a construção do lócus que contribua para o estabelecimento da condição cidadã de seus vivenciadores - conforme hipótese enunciada pelo QUAPÁ-SEL - Núcleo São Paulo (QUEIROGA et al., 2009).

A cidade brasileira caracteriza-se por ser espaço de desigualdade social, que varia de cidade a cidade, de estado a estado, existindo nas três últimas décadas grande incremento da urbanização nacional, que hoje contém grande parte da população do país. Por outro lado, as transformações da forma urbana e, portanto, de seus espaços livres têm sido drásticas nestes últimos 30 anos. Consequência das relevantes transformações sociais e econômicas, com novas formas de habitação, de estruturas locacionais e formais de indústrias e comércio e com os fatos derivados da dispersão urbana, tanto formal como funcional em andamento.

Com este Projeto Temático de Pesquisa ambiciona-se compreender as relações entre os principais agentes envolvidos no processo - concepções, produção em estrito sentido, distribuição e apropriações. Espera-se:

(1) a construção de referencial metodológico para a análise qualitativa das relações entre os sistemas de espaços livres e forma urbana, e entre estas e a estrutura ecológica pré-existente; 
(2) o estabelecimento de critérios de avaliação destas relações;

(3) a formulação de sistemas de variáveis que orientem ações propositivas de qualificação da forma urbana, considerando suas relações com os espaços livres e sua contribuição para a esfera pública. Subsidiando, portanto, na formação de insumos para ações do Poder Público;

(4) o estabelecimento de princípios de dependência entre os sistemas de espaços livres e as estruturas construídas, criando referências sobre os modelos e padrões morfológicos existentes;

(5) o estabelecimento dos tipos de implicação entre os sistemas de espaços livres e a forma urbana existente e os processos de degradação ambiental em andamento, em especial aqueles que dependem ou que se dão pela inexistência de espaços livres qualificados;

(6) a verificação do papel dos agentes públicos e privados que levam à configuração dos fenômenos detectados em 1, 4 e 5;

(7) verificação de como se distribuem as variáveis climáticas nas latitudes das cidades em estudo e seus comportamentos específicos em resposta à dinâmica dos elementos.

\section{OBJETO}

objeto deste projeto é sistema de sistemas, objeto complexo na acepção de Morin (2008), no caso o sistema de relações que se estabelecem entre sistemas de espaços livres e a forma urbana. Como realidade concreta para a investigação (concreto pensado), toma-se as metrópoles brasileiras e cidades médias do interior que apresentam, na atualidade (2010- 2014), significativa dinâmica do processo de produção do espaço urbano.

Desta maneira, e objetivando a continuidade dos trabalhos da Rede Nacional de Pesquisa QUAPÁ-SEL, escolheu-se preliminarmente as seguintes cidades ou metrópoles: Assis, Belém, Belo Horizonte, Brasília, Campina Grande, Campinas, Campo Grande, Cuiabá, Curitiba, Florianópolis, Fortaleza, Goiânia, João Pessoa, Jundiaí, Limeira, Maceió, Manaus, Maringá, Natal, Palmas, Porto Alegre, Presidente Prudente, Recife, Ribeirão Preto, Rio Branco, Rio de Janeiro, Salvador, São Carlos, São Luís, São Paulo, Santos, Sorocaba, Teresina, Uberlândia, Umuarama e Vitória ${ }^{40}$. Inclui-se, portanto, capitais de todas as regiões do país, compondo amostra bastante representativa das grandes cidades brasileiras e, também, amostra significativa de cidades de porte médio (de cem a menos de um milhão de habitantes). Para muitas das cidades trata-se de continuidade e aprofundamento da leitura e estudo novo para as demais, pois não estavam incluídas no primeiro projeto de pesquisa (as cidades acima em itálico).

privilégio pelas capitais acaba propiciando:

(1) o estudo preferencial por realidades metropolitanas, uma vez que a maioria das metrópoles brasileiras se constitui nucleada por capitais estaduais;

(2) a investigação sobre os principais modelos de urbanização contemporânea, pois o capital imobiliário de maior escala tem nas metrópoles sua maior atividade e nelas realiza o desenvolvimento de novos modelos de empreendimentos; 
(3) o estudo de legislações urbanística e ambiental, mais sofisticadas (geralmente), que acabam frequentemente servindo de modelo (de adequação questionável) para as cidades de menor porte;

(4) a análise dos investimentos públicos estaduais mais expressivos nos sistemas de espaços livres, pois têm nas capitais seu lócus preferencial;

(5) a análise dos investimentos municipais no setor;

(6) o estudo dos principais investimentos privados no tecido urbano, tanto de programas específicos, "Minha Casa, Minha Vida", como na constituição de loteamentos e condomínios fechados; nesta nova etapa será dada atenção especial à produção privada, nas suas diversas escalas, de fato a principal responsável pela constituição do tecido urbano de qualquer cidade e, portanto, de seu sistema de espaços livres.

(7) a investigação dos investimentos e políticas federais para o setor habitacional;

(8) a abrangência conveniente do território nacional, pois permite a avaliação de realidades díspares, ao mesmo tempo em que permite criar referências urbanísticas e paisagísticas.

A seleção de cidades médias, sobretudo interioranas, agrega à discussão das metrópoles e capitais, a questão da difusão da cultura urbanística dos principais centros urbanos nacionais e as especificidades de processos locais. Também, permite-se comparar processos distintos entre as cidades médias, dada a inserção diferenciada das cidades selecionadas em suas respectivas redes urbanas, algumas são centros regionais afastados das metrópoles, outras integram complexos metropolitanos expandidos.

\section{OBJETIVO GERAL}

Compreender as principais relações processuais contemporâneas entre sistemas de espaços livres e forma urbana das cidades brasileiras, entendendo o papel dos agentes envolvidos - o Estado, o mercado, os vivenciadores - no processo de produção, lato sensu, do espaço urbano.

\section{OBJETIVOS ESPECÍFICOS}

- Compreender as principais estruturas da forma urbana e sistemas de espaço livre da cidade brasileira;

- Sistematizar as formas urbanas de cada localidade em pauta, de modo a se ter visão geral e crítica do principal conjunto de formas urbanas da cidade brasileira, até hoje desconhecido em sua totalidade, o que é fundamental para futuras ações e estudos;

- Estabelecer procedimentos de método de análise qualitativa e critérios de avaliação dos sistemas de espaços livres e formas urbanas no que tange:

(1) ao seu potencial desempenho para o estabelecimento da vida pública;

(2) ao grau de obsolescência e vitalidade de diferentes tipos de espaços livres e formas construídas; 
(3) ao entendimento de significados cotidianos e simbólicos;

(4) à sua contribuição ambiental: drenagem, microclima, macroclima, estabilidade do solo, conservação e dinâmica ecológica (manguezais, dunas, florestas urbanas, cerrados, etc.);

(5) a discussão de alternativas projetuais dos espaços livres existentes e suas relações com tecidos urbanos preexistentes.

- Contribuir para propostas de políticas públicas - planos e projetos - que visem à qualificação dos sistemas de espaços livres e das formas urbanas no que concernem aos itens citados acima.

- Gerar material gráfico e iconográfico específico, que contribuam para este estudo, para o acervo do Laboratório QUAPÁ e dos centros de pesquisa parceiros, de modo a colaborar neste estudo, em estudos correlatos e a demandas do público em geral.

\section{MÉTODO}

Parte-se do princípio que:

- a sociedade e a cidade brasileira são desiguais, em termos sociais e econômicos, tanto entre si como em seu interior, sendo a desigualdade de renda da população o principal indutor das características e da conformação do espaço e da paisagem urbana;

- que os padrões de urbanização estão totalmente vinculados ao modelo de transporte priorizado, a do veiculo automotor, que associado com o desenvolvimento tecnológico e a qualificação e expansão dos sistemas viário e rodoviário determinam novas formas de mancha e tecido urbano e a dispersão física e/ou funcional dos núcleos urbanos dos mais diferentes portes;

- toda cidade tem sistema de espaços livres e forma urbana determinada e que entre as cidades estas figuras têm elementos comuns entre si e outros tantos específicos;

- que as formas de apropriação dos espaços livres têm lógicas comuns, que de certo modo permitem a identificação de similaridades e especificidades;

- que a conservação ambiental, apesar de ser parte da agenda urbanística, de fato não correspondeu a resultados consistentes em termos urbanísticos, tanto pela falta de recursos aplicados como pela dificuldade dos grupos envolvidos de enfrentar os confrontos com os processos e demandas da urbanização e vice-versa;

- o Poder Público é o principal produtor e gestor dos espaços livres de recreação e conservação, não investindo, em geral, recursos suficientes para o atendimento das demandas da população e ambientais;

- a iniciativa privada, constantemente, tem lançado novos produtos no mercado, como condomínios habitacionais e corporativos de todos os tipos e dimensões, loteamentos fechados e resorts, habitações populares, shopping centers;

- existe conhecimento acumulado suficiente nos diversos centros de pesquisa da rede Quapá - Sel sobre forma urbana e, em especial, sobre espaços livres que permitem que se iniciem estudos consistentes sobre o assunto. As referências teóricas e metodológicas 
existentes no Laboratório QUAPÁ, acumuladas desde seu início em 1995, e os trabalhos de seus pesquisadores e seus orientandos, assim como de outras áreas de pesquisa da FAUUSP, em especial dos grupos associados, constituem bases consistentes para iniciar os trabalhos de pesquisa.

Tendo em vista estas premissas e este conhecimento acumulado, pretende-se atingir os objetivos acima enunciados com as seguintes ações:

(1) revisão da bibliografia para o aprofundamento da fundamentação teórica; ; ;

(2) revisão da bibliografia referente ao "estado da arte";

(3) leitura das legislações urbanística e ambiental, referentes aos estudos de caso e realização de modelos digitais das volumetrias possibilitadas segundo os parâmetros impostos pela lei de modo a investigar os tipos de espaços livres gerados e as estruturas das formas urbanas possíveis;

(4) realização de oficinas temáticas, com duas finalidades distintas. Seriam:

tipo 1 - ou tradicional, com duração de três dias e seguindo o modelo das efetuadas anteriormente no projeto de pesquisa QUAPÁ-SEL, buscando entender o sistema de espaços livres local e a morfologia da cidade em questão. Serão efetuadas, neste formato, com três dias de duração, apenas nas cidades não pesquisadas anteriormente:

dia 1 - visita de campo guiada e sobrevoo pelos pesquisadores de São Paulo e locais;

dia 2 - apresentação pela comunidade local dos estudos referentes ao assunto em pauta na forma de palestras e debates;

dia 3 - atividade coletiva/prática de avaliação por meio de mapas e dados do sistema de espaços livres locais, tendências de crescimento urbano, conflitos ambientais e programas de ação estatais e privados e formulação de mapas e tabelas-síntese sobre o assunto.

tipo 2 - buscando discutir questões específicas sobre forma urbana e espaços livres, sendo efetuadas em dois dias:

dia 1 - apresentação pela comunidade local dos estudos referentes ao assunto em pauta na forma de palestras e debates;

dia 2 - atividade coletiva/prática envolvendo todos os componentes e focando sobre as relações espaços livres/forma urbana, com a formulação de mapas temáticos de tecidos urbanos, investimentos públicos e privados e dinâmica ecológica e tabelas e mapa-síntese de conflitos e potenciais.

Nas cidades em que foram feitos voos há mais de três anos se prevê novo voo para atualização de dados e, portanto, um dia a mais de atividades.

No caso, entende-se como oficina, reuniões de trabalho promovidas pelo grupo de pesquisa local, congregando agentes públicos e privados locais e pesquisadores universitários, que trarão informações sintetizadas do estado da arte local sobre os assuntos em pauta e farão trabalho coletivo de análise das ações em andamento e do sistema e da forma urbana existente, com ênfase nos atributos qualitativos de uso, ambientais e na forma urbana existente. Para este projeto os objetivos em pauta serão aqueles elencados anteriormente. 
(5) elaboração de mapas temáticos utilizando bases para ArcGis e fotos aéreas:

i. de padrões do tecido urbano (em anexo protótipo deste tipo de mapa);

ii. de cobertura arbórea urbana intraquadra e viária;

iii. de dinâmica ambiental: confrontando a ocupação urbana/mancha urbana frente ao suporte físico, analisando a cobertura vegetal, drenagem, rede hídrica, tipo de solo, impactos nas estruturas naturais e ecossistemas significativos;

iv. de espaços ocupados por loteamentos fechados e condomínios de grande porte (mais de um hectare);

v. de densidades urbanas - populacional e habitacional;

vi. elaboração de mapas-síntese por cidade, enfatizando as dinâmicas urbanas, ou seja, confrontando a ocupação urbana consolidada e em curso frente às estruturas naturais, expansão urbana, novos tecidos, distribuição da população e infraestrutura;

vii. mapeamento de APPS urbanas de fato existentes e determinadas pela legislação.

(6) interpretações de levantamentos de campo e dos mapas realizados no Projeto QUAPÁ-SEL I, confrontando-se com produção cartográfica do QUAPÁ-SEL II (mapa de padrões de tecido urbano e mapa de cobertura arbórea); confrontando as determinantes locais de clima com os canyons criados pela forma urbana local;

(7) construção de modelos tridimensionais de tipos de espaços livres e volumetrias mais frequentemente encontradas;

(8) estudos climáticos específicos sobre as cidades em questão e sua relação com os espaços livres e a forma urbana, de modo a validar ou não padrões existentes;

(9) estudos das dinâmicas do mercado imobiliário, seus novos produtos e sua relação com as configurações urbanas, novas e preexistentes;

(10) estudos das dinâmicas populacionais com utilização de dados produzidos pelos censos demográficos (2000-2010) desagregados por setor censitário;

(11) estudos de caso sobre a apropriação de subsistemas de espaços livres e forma urbana na escala intraurbana, cotejando com dados quantitativos e microclimáticos (por intermédio de iniciações científicas e mestrados);

(12) continuidade na realização de Colóquios anuais internos à Rede Nacional QUAPÁ-SEL para socialização de resultados, aperfeiçoamentos de método, aproximação das diferentes abordagens e formulação de conceitos comuns. O Colóquio de $\mathrm{n}$. 6 será realizado em São Paulo no início do segundo semestre de 2010;

(13) análises parciais e gerais dos resultados;

(14) elaborações de artigos para publicação de resultados parciais;

(15) elaboração de texto-síntese/livro com resultados finais do Projeto Temático.

Pela escala de abrangência e pela complexidade temática a equipe São Paulo/Laboratório QUAPÁ, além da participação dos pesquisadores da Rede Nacional QUAPÁ-SEL estabelecida, contará com a participação de consultores das áreas a seguir, sugerindo-se às demais equipes a criação de grupos multidisciplinares. Seriam elas:

- aferição de dados macro e microclimáticos em espaços livres e diferentes formas urbanas (Dr. Ricardo Augusto Felício e Dr. Jaschke Machado - Geografia/USP, Geografia/UNESP Presidente Prudente); 
- produção imobiliária e forma urbana (Dr. João Meyer - AUT-FAUUSP);

- políticas públicas habitacionais e forma urbana (Dr. João Sette Whitaker - LABHAB-FAUUSP);

- geografia crítica da forma urbana (Dra. Vanderli Custódio - IEB-USP);

-dinâmicas populacionais e forma urbana (Dr. Manoel Lemes da Silva Neto - POSURB/PUC-Campinas).

\section{RESULTADOS}

Este projeto temático de pesquisa tem como resultados esperados:

- a formulação de quadro teórico-conceitual atinente à realidade atual das grandes cidades brasileiras e, com maior aderência, evidentemente, às cidades e metrópoles selecionadas para esta pesquisa;

- o estabelecimento de método de análise de relações entre sistemas de espaços livres e forma urbana aplicáveis à realidade nacional;

- a constituição de amplo quadro nacional referente às relações entre os atuais processos de produção dos sistemas de espaços livres e das formas urbanas e os padrões formais estabelecidos em cada cidade, derivados dos procedimentos vernaculares e de mercado e ainda da legislação urbanística e ambiental existente;

- o entendimento do comportamento climático nas cidades avaliadas e as supostas respostas destas a tal contexto climático, isto é, os padrões de espaços livres e formas existentes e sua adequação a tais contextos;

- a proposição de sistema de critérios de avaliação da qualidade dos sistemas de espaços livres e formas urbanas considerando seu potencial para a vida urbana e seu desempenho ambiental;

- a formulação de críticas gerais e específicas sobre o assunto a partir de parâmetros de análise que considerem sistemicamente as variáveis envolvidas, evitando-se, portanto, a formulação de "manuais da forma urbana";

- o fortalecimento da Rede Nacional QUAPÁ-SEL e de procedimentos de pesquisa que considerem a contribuição multidisciplinar e interdisciplinar;

- a formação e o aperfeiçoamento de pesquisadores em diferentes níveis (da iniciação científica ao pós-doc);

- a publicação de resultados parciais em revistas científicas da área e em eventos científicos;

- a publicação final de livro com divulgação dos resultados. 


\section{Cronograma}

\begin{tabular}{|c|c|c|c|c|c|c|c|c|c|c|}
\hline $\begin{array}{l}\text { Atividade por ano } \\
\text { e semestre }\end{array}$ & $\begin{array}{c}\text { Ano } \\
1 \\
\text { Sem } \\
1\end{array}$ & $\begin{array}{l}\text { Ano } \\
1 \\
\text { Sem } \\
\text { II }\end{array}$ & $\begin{array}{c}\text { Ano } \\
2 \\
\text { Sem } \\
1\end{array}$ & $\begin{array}{l}\text { Ano } \\
2 \\
\text { Sem } \\
\text { II }\end{array}$ & $\begin{array}{l}\text { Ano } \\
3 \\
\text { Sem } \\
1\end{array}$ & $\begin{array}{l}\text { Ano } \\
3 \\
\text { Sem } \\
\text { II }\end{array}$ & $\begin{array}{l}\text { Ano } \\
4 \\
\text { Sem } \\
\text { I }\end{array}$ & $\begin{array}{c}\text { Ano } \\
4 \\
\text { Sem } \\
\text { II }\end{array}$ & $\begin{array}{c}\text { Ano } \\
5 \\
\text { Sem } \\
1\end{array}$ & $\begin{array}{l}\text { Ano } \\
5 \\
\text { Sem } \\
\text { II }\end{array}$ \\
\hline $\begin{array}{l}\text { Leitura de } \\
\text { fundamentação } \\
\text { teórica }\end{array}$ & & & & & & & & & & \\
\hline Leitura temática & & & & & & & & & & \\
\hline $\begin{array}{l}\text { Leitura e } \\
\text { interpretação de } \\
\text { legislação }\end{array}$ & & & & & & & & & & \\
\hline $\begin{array}{l}\text { Formatação de } \\
\text { modelos/volu- } \\
\text { metrias derivadas } \\
\text { de legislação e } \\
\text { vernaculares }\end{array}$ & & & & & & & & & & \\
\hline Oficinas & & & & & & & & & & \\
\hline Colóquios & & & & & & & & & & \\
\hline $\begin{array}{l}\text { Mapas de tecidos } \\
\text { urbanos }\end{array}$ & & & & & & & & & & \\
\hline $\begin{array}{l}\text { Mapas de cobertura } \\
\text { arbórea }\end{array}$ & & & & & & & & & & \\
\hline $\begin{array}{l}\text { Mapas de dinâmicas } \\
\text { ambientais e estudos } \\
\text { climáticos }\end{array}$ & & & & & & & & & & \\
\hline $\begin{array}{l}\text { Interpretação } \\
\text { cartográfica }\end{array}$ & & & & & & & & & & \\
\hline $\begin{array}{l}\text { Análise do material } \\
\text { fotográfico }\end{array}$ & & & & & & & & & & \\
\hline Mapas-síntese & & & & & & & & & & \\
\hline $\begin{array}{l}\text { Estudos de caso } \\
\text { (apropriação), } \\
\text { estudos climáticos, } \\
\text { etc. }\end{array}$ & & & & & & & & & & \\
\hline $\begin{array}{l}\text { Análises e } \\
\text { interpretações finais }\end{array}$ & & & & & & & & & & \\
\hline $\begin{array}{l}\text { Divulgação de } \\
\text { resultados parciais }\end{array}$ & & & & & & & & & & \\
\hline $\begin{array}{l}\text { Redação de } \\
\text { publicação final }\end{array}$ & & & & & & & & & & \\
\hline
\end{tabular}




\section{Notas}

1 Entre os pioneiros dos estudos morfológicos no país estão: Benamy Turkienicz, Frederico Holanda, Maria Elaine Kohlsdorf e Vicente Del Rio Nascimento.

2 MASCARÓ, Juan L. Infra-estrutura da Paisagem. Porto Alegre: Masquatro, 2008. . Loteamentos Urbanos. Porto Alegre: Masquatro, 2005.[2003] MASCARÓ, Juan L.; YOSHINAGA, Mario. Infra-estrutura Urbana. Porto Alegre: Masquatro, 2005. MASCARÓ, Lucia E. A. R. de; MASCARÓ, Juan L. Vegetação Urbana. Porto Alegre: L. Mascaró, J. Mascaró, 2002.

3 O projeto QUAPÁ-SEL estudou, prioritariamente, com diferentes graus de profundidade, as seguintes cidades ou regiões metropolitanas: Araraquara, Bauru, Belém, Belo Horizonte, Brasília, Campinas, Campo Grande, Curitiba, Florianópolis, Fortaleza, Jundiaí, Limeira, Maceió, Manaus, Maringá, Natal, Palmas, Piracicaba, Porto Alegre, Recife, Ribeirão Preto, Rio Branco, Rio de Janeiro, Salto, Salvador, São Carlos, São Luís, São Paulo, Santa Maria, Sorocaba, Suzano e Vitória.

4 Santos, M. (2002, p. 99) explicita: "Para alcançar o conhecimento, a forma nos dá um ponto de partida, mas está longe de nos dar um ponto de chegada, sendo insuficiente para oferecer, sozinha, uma explicação."

5 Áreas de Proteção Permanente.

6 Conforme SANTOS, M. (2005, p.62): “Um problema analítico importante vem do fato de que, em um sistema urbano, as aglomerações são, todas, objetos geográficos ou, ainda melhor, uma coleção de objetos geográficos, isto é formas." Ainda em SANTOS, M. (2002, p.66): "[...] objetos fixos: uma ponte, uma casa, um porto, uma estação de estrada de ferro, uma usina hidroelétrica, uma cidade, um campo, uma plantação são, pelos geógrafos, considerados objetos geográficos."

7 MOLES, Abraham. Les objetos. Buenos Aires: Editorial Tiempo Contemporâneo, 1971.

8 Apud LAMAS, José M. R. G.. Morfologia urbana e desenho da cidade. Lisboa: Fundação Calouste Gulbelkian, 1993, p.44.

9 DEL RIO, Vicente. Introdução ao desenho urbano no processo de planejamento. São Paulo: Pini, 1990.

10 MOUDON, Anne V. A catholic approach to organizing what urban designers should know, 1992. In: CUTHBERT, Alexander. Designing cities: Critical readings in urban design. Malden: Oxford, Victoria: Blackwell Publishing, 2003.

11 CARMONA, Matthew, et al. Public place. Urban spaces: The dimensions of urban design. Oxford: Burlington/ Architectural Press, 2003.

12 CUTHBERT, Alexander. The form of cities: Political economy and urban design. Malden: Oxford, Victoria: Blackwell Publishing, 2006.

13 CANTER, David. The psicology of place. Londres: Architectural Press, 1977.

14 MUMFORD, Lewis. The city in history. Nova York: Harcourt books, 1989.[1961].

15 BENEVOLO, Leonardo. História da cidade. São Paulo: Perspectiva, 2003 [1980].

16 MORRIS, Anthony. History of urban form. Before the Industrial Revolutions. Londres: Longman, 1979.

17 KOSTOF, Spiro. The city shaped: Urban patterns and meanings through history. Boston: Bullfinch Press / little Brown, 2002. [1991].

18 CULLEN, Gordon. Paisagem urbana. Lisboa: Edições 70, 1983. [1961].

19 SITTE, Camillo. City planning according to artistic principles. 1889.

20 UNWIN, Raymond. Town planning in practice: An introduction to the art of designing cities and suburbs. Nova York: B. Blom, 1909.

21 LYNCH, Kevin. A imagem da cidade. São Paulo: Martins Fontes, 1997. [1960].

22 ASHIHARA, Yoshinobu. The aesthetic townscape. Cambridge Mass: MIT Press, 1983.

23 LANG, Jon. Creating architectural theory: The role of the behavioral sciences in environmental design. Nova York: Van Nostrand Reinhold, 1987.

24 RAPOPORT, Amos. Human aspects of urban form: Towards a man-environment approach to urban form and design. Oxford: Pergamoin Press, 1977.

25 GEHL, Jan. Life between buildings: Using public space. Nova York: [s.n.], 1987.

26 NORBERG-SCHULZ, Christian. Genius Loci: Towards a phenomenology of architecture. Nova York: Rizzoli International Publications, 1980.

27 WHYTE, William. The social life of small urban spaces. Nova York: Project for public spaces, 1988.

28 LYNCH, Kevin. A theory of good city form. Cambridge, Mass. Londres: The MIT Press, 1981.

29 VENTURI, Robert et al. Aprendendo com Las Vegas: O simbolismo (esquecido) da forma arquitetônica. São Paulo: Cosac \& Naify, 2003. [1977]. 
30 JACKSON, John. The necessity for ruins and other topics. Amherst University of Massachusetts Press, 1980.

31 ROSSI, Aldo. A arquitetura da cidade. São Paulo: Martins Fontes, 2001. [1966].

32 AYMONINO, Carlo. O significado das cidades. Lisboa: Editorial Presença, 1984. [1975].

33 KRIER, Rob. Urban space. Nova York: Rizzoli International Publications, 1979.

34 ALEXANDER, Christopher. La ciudad no es un árbol. Cuadernos Summa. Buenos Aires: Nueva Vision, n.9, p.2030. 1971. ALEXANDER, Christopher et al. A pattern language. Nova York: Oxford University Press, 1977.

35 HILLIER, Bill \& HANSON, Julienne. The social logic of space. Cambridge: Cambridge University Press, 1984.

36 HILLIER, Bill. Space is the machine: A configurational theory of architecture. Cambridge: Cambridge University Press, 1996.

37 MCHARG, lan. Design with nature. Philadelphia: Falcon Press, 1971. [1969].

38 SPIRN, Anne. O jardim de granito: A natureza no desenho da cidade. São Paulo: Edusp, 1995. [1984].

$39 \mathrm{HOUGH}$, Michel. Cities and natural process. Londres: Rutledge, 1995.

40 As cidades em negrito serão objeto de pesquisas estruturadas pelo núcleo São Paulo e seus parceiros e as demais objeto de estudo de pesquisadores associados ao projeto.

41 Vale citar alguns autores fundamentais da base teórica que orientam o método e as interpretações analíticas:

- sobre a natureza e a produção do espaço: M. Santos (1985 e 1996);

- sobre a esfera pública: J. Habermas (1981 e 2007); H. Arendt (1991) e S. Costa (2002);

- sobre espaço público: E. Queiroga (2009); A. Serpa (2007); Macedo (1999), (2011);

- sobre a conceituação de sistema e de complexidade: E. Morin (2008);

- sobre apreensão da forma urbana: M. E. Kohlsdorf (1996); Macedo (1993); Hepner (2010).

\section{Bibliografia}

ABRAHÃO, Sérgio L. Espaço público: Do urbano ao político. São Paulo: Annablume/ FAPESP, 2008.

ACIOLY JUNIOR, Cláudio; Davidson, Forbes. Densidade urbana e gestão urbana. Rio de Janeiro: Mauad Editora, 1998.

Density in Urban Development. Building Issues. Lund, n. 3. v. 8, p. 4-25, 1996.

AKAMINE, R. A study on use of large open spaces in privately owned public spaces: Experiences from Osaka, Japan. Tese (Doutorado) - Osaka University. Osaka, 2004.

ALEXANDER, Christopher. La ciudad no es un árbol. Cuadernos Summa - Nueva Vision, n.9, p.20-30. Buenos Aires, 1971.

et al. A pattern language. Nova York: Oxford University Press, 1977.

ALVES, Guilherme G. Os espaços livres nos novos empreendimentos privados verticais na região Grande São Paulo. Iniciação Científica, 2010. Faculdade de Arquitetura e Urbanismo da Universidade de São Paulo, Fundação de Amparo à Pesquisa do Estado de São Paulo, São Paulo, 2010.

ARANTES, Antonio A. Paisagens paulistanas: Transformações do espaço público. São Paulo: Editora da Unicamp/ Imprensa Oficial, 2000.

ARANTES, Otília B. F. O lugar da arquitetura depois dos modernos. 3 ed. São Paulo: Edusp, 2000. [1993].

; MARICATO, Ermínia; VAINER, Carlos. A cidade do pensamento único: Desmanchando consensos. Petrópolis: Vozes, 2000.

ARENDT, Hannah. A condição humana (1958). 5 ed. Rio de Janeiro: Forense Universitária, 1991.

ASHIHARA, Yoshinobu. The aesthetic townscape. Cambridge Mass: MIT Press, 1983.

AYMONINO, Carlo. O significado das cidades. Lisboa: Editorial Presença, 1984. [1975].

AZEVEDO, T. R.. A frota de automóveis e o pó que São Paulo respira - particulado inalável no clima da cidade. In: Ariovaldo Umbelino de Oliveira (Org.). Geografias de São Paulo. São Paulo: Contexto, 2004.

- Ritmo semanal do campo de vento na Grande São Paulo. In: V Simpósio de Climatologia Geográfica. Anais... Curitiba, UFPR, 4 a 6 dez. 2002 (a).

. Distribuição Espacial da Ocorrência dos Maiores Totais Diários de Precipitação na RMSP e Arredores em Função da Intensidade Relativa da Atividade Urbana. GEOUSP 12, 89-104. 2002 (b). 
- fluxo de calor gerado pelas atividades humanas. Os climas na cidade de São Paulo, teoria e prática. GEOUSP 4, 71-93. 2001.

BORDIEUR, Pierre. A economia das trocas simbólicas. São Paulo: Perspectiva, 1999.

BRASIL. Lei n. 10.257, de 10 de julho de 2001. Estatuto da Cidade. Regulamenta os arts. 182 e 183 da Constituição Federal, estabelece diretrizes gerais da política urbana e dá outras providências.Disponívelem: $<$ http://www. dominiopublico.gov.br/download/texto/sf00008a.pdf>. Acesso em: 30 mai. 2011.

CAMPOS, Ana Cecília M. de A. Alphaville-Tamboré e Barra da Tijuca: As ações programadas e a estruturação do sistema de espaços livres. Tese (Doutorado) - Faculdade de Arquitetura e Urbanismo da Universidade de São Paulo. São Paulo, 2008.

CANTER, David. The psicology of place. Londres: Architectural Press, 1977.

CARDEMAN, Rogério G. Copacabana: Descobrindo os espaços livres do bairro. Dissertação (Mestrado) - PROARQ/ Faculdade de Arquitetura e Urbanismo da Universidade Federal do Rio de Janeiro. Rio de Janeiro, 2010.

CARDEMAN, David; CARDEMAN, Rogério G. O Rio de Janeiro nas alturas. Rio de Janeiro: Mauad, 2004.

CARMONA, Matthew et al. Public place. Urban spaces: The dimensions of urban design. Oxford, Burlington: Architectural Press, 2003.

CARNEIRO, Ana R.; MESQUITA, L. B. Espaços livres do Recife. Recife: Prefeitura da Cidade do Recife/ Universidade Federal de Pernambuco, 2000.

CARNEIRO, Eder Jurandir. Política ambiental e a ideologia do desenvolvimento sustentável. In: ZHOURI, Andréa; LASCHEFSKI, Klemens; PEREIRA, Doralice Barros (Orgs.). A insustentável leveza da política ambiental: Desenvolvimento e conflitos socioambientais. Belo Horizonte: Autêntica, 2005.

CARVALHO, Sydney. Entre o rio e a serra: Forma urbana e sistema de espaços livres na região norte do município de São Paulo. Dissertação (Mestrado) - Faculdade de Arquitetura e Urbanismo da Universidade de São Paulo. São Paulo, 2011.

CERTEAU, Michel de. A invenção do cotidiano: Artes de fazer. Petrópolis: Vozes, 1994.

CHEN, J.M.; OKE, T.R.. Mixed-Layer Heat Advection and Entrainment During The Sea Breeze. Boundary-Layer Meteorology, 68, 139-158. 1994.

COSTA, Lúcia Maria Sá Antunes (Org.). Rios e paisagens urbanas em cidades brasileiras. Rio de Janeiro: Viana \& Mosley/ PROURB, 2006.

COSTA, Sérgio. As cores de Ercília: Esfera pública, democracia, configurações pós-nacionais. Belo Horizonte: UFMG, 2002.

CUSTÓDIO, V. Dos surtos urbanísticos do final do século XIX ao Plano de Avenidas. Revista Geosul (UFSC), Florianópolis, v. 38, p. 1-19, 2004.

Requalificar o urbano do século XX: projeto para o centro da cidade de São Paulo - mistura ou gentrificação. In: Ana Fani Alessandri Carlos; Ariovaldo Umbelino de Oliveira. (Org.). Geografias de São Paulo: A metrópole do século XXI. São Paulo: Contexto, 2004, v. 2, p. 341-362.

Segregação, fragmentação e segmentação. In: ENCONTRO INTERNACIONAL DE GEÓGRAFOS DA AMÉRICA-LATINA, X, 2005, São Paulo. Anais do X EGAL. São Paulo: FFLCH/USP - Depto. de Geografia, 2005. p. 1- 16.

450 Jahre São Paulo: Eine Stadt in Scherben. Die Urbanisierung von São Paulo. Brasilien-Dialog, Mettingen,

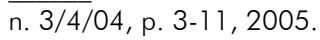

Inundações no espaço urbano: As dimensões natural e social do problema. Terra Livre, São Paulo: AGB Nac., jan./jun., v. 1, n. ano 21, p. 193-210, 2005.

La production du manque d'eau dans la région métropolitaine de São Paulo (RMSP). Confins (Paris), v. 1, p. 1-15, 2010.

CUTHBERT, Alexander. The form of cities: Political economy and urban design. Malden: Oxford, Victoria: Blackwell Publishing, 2006.

DEL RIO, Vicente. Introdução ao desenho urbano no processo de planejamento. São Paulo: Pini, 1990.

; SIEMBIEDA, William (Orgs.). Beyond Brasília: Contemporary urbanism in Brazil. Gainesville: University Press of Florida, 2008.

DOUGLAS, I.. The urban environment. Londres: Edward Arnold, 1983. 
FARIA, Geraldo. Configuração da esfera pública e produção da paisagem. In: ENCONTRO NACIONAL DE ENSINO DE PAISAGISMO EM ESCOLAS DE ARQUITETURA E URBANISMO NO BRASIL, IX, 2008, Curitiba. Anais do IX ENEPEA. Curitiba: UFPR, 2008. (no prelo)

FAORO, Raymundo. Os donos do poder: Formação do patronato político brasileiro. 13 ed. São Paulo: Globo, 1998. [1957]. 2v.

FERREIRA, João Sette Whitaker. O mito da cidade global: $\bigcirc$ papel da ideologia na produção do espaço urbano. Petrópolis: Vozes; São Paulo: Editora Unesp; Salvador: Anpur, 2007.

FOUCAULT, Michel. Microfísica do poder (1979). 14 ed. Rio de Janeiro: Grahal, 1999.

FREITAS, Ruskin. Entre mitos e limites: As possibilidades do adensamento construtivo face à qualidade de vida no ambiente urbano. Recife: Ed. Universitária da UFPE, 2008.

GALENDER, F.; CAMPOS, A. C.; MACEDO, S. (et al.). Políticas e ações públicas para implantação de sistemas de espaços livres: a experiência de Sorocaba. In: ENCONTRO NACIONAL DE ENSINO DE PAISAGISMO EM ESCOLAS DE ARQUITETURA E URBANISMO NO BRASIL, X, 2010, Porto Alegre. Anais do X ENEPEA. Porto Alegre: PUCRS, 2010.

GEHL, Jan. Life between buildings: Using public space. Nova York: [s.n.], 1987.

GEIGER, R.; ARON, R. H.; TODHUNTER, P.. The climate near the ground. Lanham: Rowman \& Littlefield Publishers, Inc. 2003.

GOMES, Paulo C.. A condição urbana: Ensaios de geopolítica da cidade. 2 ed. Rio de Janeiro: Bertrand Brasil, 2006.

GRIMMOND, C. S. B.; OKE T. R.. Comparison of Heat Fluxes from Summertime Observations in the Suburbs of Four North American Cities. Journal of Applied Meteorology, 34, 873 - 889. 1995.

; KING, T. S.; CROPLEY, F. D.; NOWAK, D. J.; SOUCH, C.. Local-Scale Fluxes of Carbon Dioxide in Urban Environments: Methodological challenges and results from Chicago. Environmental Pollution. 116, 243 - 254. 2002.

HABERMAS, Jürgen. Mudança estrutural da esfera pública: Investigações quanto a uma categoria da sociedade burguesa (1962). Rio de Janeiro: Tempo Brasileiro, 1984.

. The theory of communicative action (1981). Boston: Beacon Press, 1989. 2 v., v. 2.

O discurso filosófico da modernidade (1985). Lisboa: Dom Quixote, 1990.

. Entre naturalismo y religión (2005). Barcelona: Paidós, 2006.

A inclusão do outro: Estudos de teoria política (1996). 3 ed. São Paulo: Loyola, 2007.

HARVEY, David. Espaços de esperança. São Paulo: Loyola, 2004.

HELLER, Agnes. O cotidiano e a história (1970). 4 ed. Rio de Janeiro: Paz e Terra, 1996.

HEPNER, Alexandre. Desenho urbano, capital e ideologia em São Paulo: Centralidade e forma urbana na marginal do rio Pinheiros. Dissertação (Mestrado) - Faculdade de Arquitetura e Urbanismo da Universidade de São Paulo. São Paulo, 2010.

HOUGH, Michel. Cities and natural process. Londres: Routledge, 1995.

JACKSON, John. The necessity for ruins and other topics. Massachusetts: Amherst University of Massachusetts Press, 1980.

JACOBS, Jane. Morte e vida de grandes cidades. São Paulo: Martins Fontes, 2000. [1961].

JOHNSON, G. T.; OKE, T. R.; LYONS, T. J.; STEYN, D. G.; WATSON, I. D.; VOOGT, J. A.. Simulation of Surface Urban Heat Islands Under 'Ideal' Conditions At Night, Part 1: Theory And Tests Against Field Data, Boundary-Layer Meteorology, 56, 275-294. 1991.

KOHLSDORF, M. E. A apreensão da forma da cidade. Brasília: UnB, 1996.

KOSTOF, Spiro. The city shaped: Urban patterns and meanings through history. Boston: Bullfinch Press / Little Brown, 2002. [1991].

KRIER, Rob. Urban space. Nova York: Rizzoli International Publications, 1979.

LANG, Jon. Creating architectural theory: The role of the behavioral sciences in environmental design. NovaYork: Van Nostrand Reinhold, 1987. 
LEFEBVRE, H.. O direito à cidade. São Paulo: Centauro Editora, 2001. [1970].

La production de I'espace. Paris: Anthropos, 1974.

LEITE, Rogério. Contra-usos da cidade: Lugares e espaço público na experiência urbana contemporânea. Campinas: Editora da UNICAMP; Aracaju: Editora UFS, 2004.

LEMOS, João Rett. Condomínios Residenciais Horizontais em São Paulo: Um aspecto da produção paisagística contemporânea. Iniciação Científica, 2004. Faculdade de Arquitetura e Urbanismo da Universidade de São Paulo, Fundação de Amparo à Pesquisa do Estado de São Paulo, São Paulo, 2004.

MACEDO, Silvio. Paisagismo na virada do século: 1990-2010. São Paulo: Edusp, 2011 . (no prelo)

Paisagem, urbanização e litoral do Éden à cidade. Tese (Livre-docência) - - Faculdade de Arquitetura e Urbanismo da Universidade de São Paulo, São Paulo, 1993.

Quadro do paisagismo no Brasil. São Paulo: FAUUSP, 1999.

São Paulo, paisagem e habitação verticalizada: Os espaços livres como elementos de desenho urbano. Tese (Doutorado) - Faculdade de Arquitetura e Urbanismo da Universidade de São Paulo. São Paulo, 1988.

; ROBBA, Fábio. Praças brasileiras. São Paulo: Edusp/ Imprensa Oficial do Estado, 2002.

; SAKATA, Francine. Parques Urbanos no Brasil. São Paulo: Edusp/ Imprensa Oficial do Estado, 2002.

MACEDO, QUEIROGA, CAMPOS, et al. Considerações preliminares sobre o sistema de espaços livres e a constituição da esfera pública contemporânea no Brasil. In: TÂNGARI, ANDRADE, SCHLEE (Orgs.). Sistemas de espaços livres: $\bigcirc$ cotidiano, apropriações e ausências. Rio de Janeiro: UFRJ, 2009.

MACHADO, A. J.. Distribuição espacial do fluxo radiativo em ondas longas na Região Metropolitana de São Paulo. Tese (Doutorado) - Faculdade de Filosofia, Letras e Ciências Humanas da Universidade de São Paulo. São Paulo, 2009.

AZEVEDO, T. R.. Por uma compreensão adeqüada do uso de princípios radiométricos no planejamento topoclimático urbano. In: Encontro Internacional de Geografia: tradições e perspectivas, homenagem ao nascimento de Pierre Monbeig. Anais... São Paulo, 2008 (a).

; AZEVEDO , T. R.. A divergência radiativa na camada próxima ao chão. In: Anais do VIII Simpósio Brasileiro de Climatologia Geográfica, Universidade Federal de Uberlândia, Alto Caparaó, 33 - 44. 2008 (b). (CdRom) 59-70. 2007 (a)

Detection of the urban heat-island effect from a surface mobile platform. Revista de Teledetección, 27,

Parâmetros meteorológicos observados na rede telemétrica da CETESB. In: I Workshop Regional de Geografia e Mudanças Ambientais. Anais... Guarapuava, UNICENTRO, 23-32. 2007 (b).

Distribuição espacial dos termos do balanço de energia em superfície a partir de imagem orbital e observações de campo. Revista do Departamento de Geografia, 19, 81-91. 2006 (a). $\overline{198.2006}$ (b)

Parametrização da emissão termoradiativa aplicada à análise do conforto urbano. GEOUSP, 19, 179 -

Da necessidade de correção das medidas de radiação térmica obtida através de plataformas móveis em áreas urbanas. In: III Seminário de Pesquisa em Geografia Física 11 e 12 de dezembro, Universidade de São Paulo, 37 - 48. 2006 (c). (CdRom)

. Fluxo diurno de radiação de onda longa recebida em um trajeto urbano arborizado. In: XI Simpósio Brasileiro de Geografia Física Aplicada. Universidade de São Paulo, 100 - 109. 2005. (CdRom)

Observações não convencionais da radiação atmosférica na CUASO e imediações. In: II Seminário de Pesquisa em Geografia Física 11 e 12 de dezembro, Universidade de São Paulo, 657 - 662. 2004. (CdRom)

MAGNOLI, Miranda M. E. M.. Espaços livres e urbanização: Uma introdução a aspectos da paisagem metropolitana. Tese (Livre-Docência) - Faculdade de Arquitetura e Urbanismo, Universidade de São Paulo. São Paulo, 1982.

MARANGONI, A. M. M. C.. Questionários e entrevistas - algumas considerações. In: Venturi, L. A. B. (Org.). Praticando Geografia: Técnicas de campo e laboratório. São Paulo: Oficina de textos, 2005.

MARCUS, Claire Cooper; FRANCIS, Carolyn. People Places: Design Guidelines for Urban Open Space. 2 ed. Nova York: John Wiley \& Sons, 1998.

MARICATO. Ermínia. Metrópole na periferia do capitalismo: ilegalidade, desigualdade e violência. São Paulo: Hucitec, 1966 (Série Estudos Urbanos).

MASSON, V., GRIMMOND, C. S. B. and OKE, T. R. (2002). Evaluation of the Town Energy Balance (TEB) scheme with direct measurements from dry districts in two cities. Journal of Applied Meteorology, 41, p. 101 1-1026. 
MCHARG, lan. Design with nature. Philadelphia: Falcon Press, 1971. [1969].

MENDONÇA, Eneida. Apropriações do espaço público: Alguns conceitos. Estudos e Pesquisas em Psicologia (on-line), v. 2, Rio de Janeiro, p. 122-132, 2007

MEYER, Regina P.. O papel da rua na urbanização paulistana. In: A cidade e a rua. Cadernos de História de São Paulo, n.2. São Paulo: Museu Paulista da Universidade de São Paulo, 1993. p. 13-26.

MOLION, L. C. B.. Aquecimento global - uma visão crítica. In: Veiga, J. E. da (Org.). Aquecimento global: Frias contendas científicas. São Paulo: Editora SENAC, 2008.

MORAES, Antônio Carlos R.. Meio ambiente e ciências humanas. São Paulo: Hucitec, 1994.

MORIN, E. (1979). O método 1: A natureza da natureza. 2. ed. Porto Alegre: Sulina, 2008.

MORRIS, Anthony. History of urban form. Before the Industrial Revolutions. Londres: Longman, 1979.

MOUDON, Anne V. A catholic approach to organizing what urban designers should know, 1992. In: CUTHBERT, Alexander. Designing cities: Critical readings in urban design. Malden: Oxford; Victoria: Blackwell Publishing, 2003.

OKE, T. R. Boundary Layer Climates. Londres and John Wiley \& Sons, New York, 435p, 1987.

Proceedings WMO Technical Conference on Urban Climatology and its Applications with Special Regard to Tropical Areas, 1986.

. The micrometeorology of the urban forest, Philosophical Ttransactions of the Royal Society of London, B 324, 335-349. 1989.

. Boundary Layer Climates. 2 ed. Londres: Routledge, 1987.

; JOHNSON, G. T.; STEYN, D. G.; WATSON, I. D.. Simulation of nocturnal surface urban heat islands under 'Ideal' conditions: Part 2. Diagnosis of causation, Boundary-Layer Meteorology, 56, 339-358. 1991.

OLGYAY, V. Arquitectura y clima - manual de diseño bioclimático para arquitectos y urbanistas. Barcelona: Editorial Gustavo Gili. 2008.

ONÇA, D. S.. "Quando o sol brilha, eles fogem para a sombra..." - a ideologia do aquecimento global. Tese (Doutorado) - Faculdade de Filosofia, Letras e Ciências Humanas da Universidade de São Paulo. São Paulo, 2011.

PAISAGEM E AMBIENTE: ENSAIOS - n.21. São Paulo: FAUUSP, 2006.

PAISAGEM E AMBIENTE: ENSAIOS - n.26. São Paulo: FAUUSP, 2009.

PEREIRA COSTA, Stael de Alvarenga. As expansões das cidades brasileiras: Um processo sem fim. Paisagem e ambiente, São Paulo, v. 22, n. I, p. 257-263, 2006.

Transformações, conflitos, perdas e permanências na paisagem sul- metropolitana de Belo Horizonte. Belo Horizonte, 2004. v. 1, 317 p.

; PERNA, Stefânia de Araúio; SIMÃO, Karina Machado de Castro. O estudo da forma urbana no Brasil. Arquitextos, v. 087, p. 87, 2007.

PENALOSA, Enrique. Politics, power, cities. In: BURDETT, Ricky; SUDJIC, Deyan. The endless city. Londres: Phaidon Press, 2007. p. 307-319.

QUEIROGA, E.. Por um paisagismo crítico: Uma leitura sobre a contribuição de Miranda Magnoli para a ampliação do corpus disciplinar do Paisagismo. Paisagem e ambiente, São Paulo, v. 21, n. 22, p. 94-106, 2006.

. Espacialidades da esfera pública na urbanização contemporânea: Casos na Megalópole do Sudeste. In: $\overline{M A G N O L I}$, Miranda; KAHTOUNE, Saide; TOMINAGA, Yassuko (Org.). Paisagens em debate. São Carlos: RiMa, 2007. p. 121-142.

; BENFATTI, Denio. Sistemas de espaços livres urbanos: construindo um referencial teórico. Paisagem e ambiente: Ensaios, n. 24, São Paulo, p. 81-87, 2007.

; CUSTODIO, V.; CAMPOS, A. C. (et al). Os espaços livres e a esfera pública contemporânea: Por uma conceituação considerando propriedades (públicas e privadas) e apropriações. In: TÂNGARI, Vera; ANDRADE, Rubens de; SCHLEE, Mônica. (Orgs.). Sistema de espaços livres: $O$ cotidiano, apropriações e ausências. Rio de Janeiro: PROARQ/FAU-UFRJ, 2009, v., p. 84-99.

RAPOPORT, Amos. Human aspects of urban form: Towards a man-environment approach to urban form and design. Oxford: Pergamo in Press, 1977.

REIS, Nestor Goulart. Notas sobre a urbanização dispersa e novas formas de tecido urbano. São Paulo: Via das Artes, 2006. 
Silvio Soares Macedo, Eugenio Fernandes Queiroga, Fany Cutcher Galender, Ana Cecília de Arruda Campos, Vanderli Custódio, Helena Degreas, Fabio Mariz Gonçalves

RIBEIRO, H.; AZEVEDO, T. R. de. O patrimônio em áreas verdes da USP e a atmosfera urbana. In: Comissão de Patrimônio Cultural da USP (Org.). Meio ambiente: Patrimônio cultural da USP. São Paulo: Edusp / Imprensa Oficial, 2003.

ROCHLITZ, Rainer (Coord.). Habermas: O uso público da razão (2002). Rio de Janeiro: Tempo Brasileiro, 2005.

ROSS, S. L.; OKE, T. R. Tests of three urban energy balance models, Boundary-Layer Meteorology, 44, 73-96. 1988.

ROUANET, Sérgio Paulo. As razões do Iluminismo. São Paulo: Companhia das Letras, 1987.

SAKATA, Francine G.. Paisagismo urbano: Requalificação e criação de imagens. São Paulo: Edusp, 2011.

SAKAMOTO, L. L. S.. Os microclimas e a "Configuração do Céu" na área central. Os Climas na cidade de São Paulo, teoria e prática. GEOUSP 4, 165 - 187. 2001.

SANTOS, C. N. F. dos. A cidade como um jogo de cartas. São Paulo: Projeto, 1988.

SANTOS, M. O. Estimativa de dados, distribuição espacial sazonal, representação e análise do fluxo de radiação direta na região metropolitana de São Paulo. Monografia de conclusão de graduação apresentada ao Departamento de Geografia da Faculdade de Filosofia, Letras e Ciências Humanas da Universidade de São Paulo. 2009.

In Desenho Urbano I. I Seminário sobre Desenho Urbano no Brasil. Cadernos Brasileiros de Arquitetu-

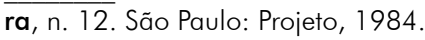

Quando a rua vira casa. 2 ed. Rio de Janeiro: Zahar, 1981.

SANTOS, M.. A natureza do espaço: Técnica e tempo, razão e emoção. São Paulo: Hucitec, 1996.

A urbanização brasileira. 5 ed. São Paulo: Edusp, 2005. (Coleção Milton Santos, 6).

Espaço e método. São Paulo: Nobel, 1985.

SAUNDERS, William S. (ed.). Sprawl and suburbia. Minneapolis: University of Minnesota Press, 2005.

SARDÃO, Ulisses D. C.. Os espaços livres particulares produzidos nos condomínios. Iniciação Científica, 2009. Faculdade de Arquitetura e Urbanismo da Universidade de São Paulo, Fundação de Amparo à Pesquisa do Estado de São Paulo, São Paulo, 2009.

SERPA, Ângelo. O espaço público na cidade contemporânea. São Paulo: Contexto, 2007.

SILVA, Carlos E. M.. Lugar-hábitat e lugar-mercadoria: Territorialidades em tensão no domínio dos cerrados, 2005, p.217-144. In: ZHOURI, Andréa; LASCHEFSKI, Klemens; PEREIRA, Doralice Barros (Orgs.). A insustentável leveza da política ambiental: Desenvolvimento e conflitos socioambientais. Belo Horizonte: Autêntica, 2005.

SOUZA, Maria Adélia (2006). Meio ambiente e desenvolvimento sustentável: As metáforas do capitalismo. Disponível em: <http://www.territorial.org.br>. Acesso em julho de 2010.

(Org.). A metrópole e o futuro: Refletindo sobre Campinas. Campinas: Editora Instituto Territorial, 2008.

SPREIREGEN, Paul D. Urban design: The architecture of towns and cities. Nova York: McGraw-Hill, 1965.

SPIRN, Anne. O jardim de granito: A natureza no desenho da cidade. São Paulo: Edusp, 1995. [1984].

TAKAESU, Luciana Satiko. Os espaços livres da habitação verticalizada em São Paulo. Iniciação Científica, 2009. Faculdade de Arquitetura e Urbanismo da Universidade de São Paulo, Fundação de Amparo à Pesquisa do Estado de São Paulo, São Paulo, 2009.

TÂNGARI, V. R. The urban landscape of the northern zone of Rio de Janeiro: A morphological study. In: XIII International Seminar on Urban Form Conference, 2007, Ouro Preto e XIII International Seminar on Urban Form ConferenceProceedings. Anais... Belo Horizonte: FAU/UFMG-UFOP, 2007. v. 1.

TÂNGARI, Vera Regina; ANDRADE, Rubens de; SCHLEE, Mônica Bahia (Orgs.). Sistema de espaços livres: $\bigcirc$ cotidiano, apropriações e ausências. Rio de Janeiro: PROARQ/ FAU/UFRJ, 2009.

TARIFA, J. R.; ARMANI, G.. Os climas urbanos. Os climas na cidade de São Paulo, teoria e prática. GEOUSP 4, 47 - 70. 2001.

TURKIENICZ, Benamy (Org.). Desenho urbano I. I Seminário sobre desenho urbano no Brasil. Cadernos Brasileiros de Arquitetura, n. 12. São Paulo: Projeto, 1984.

TURKIENICZ, B, MALTA, M. (Org.). Desenho urbano. Seminário sobre desenho urbano no Brasil. Anais do II SEDUR. São Paulo: Pini; Brasília: CNPq; Rio de Janeiro: FINEP, 1986. 
VOOGT, J. A.; GRIMMOND, C. S. B.. Modeling surface sensible heat flux using surface radiative temperatures in a simple urban area. Journal of Applied Meteorology, 39, 1679 - 1699. 2000.

VOOGT, J. A.; OKE, T. R. . Complete urban surface temperatures. Journal of Applied Meteorology, $36,1117-$ 1132, 1997.

WEINGARTNER, Guttemberg. A construção de um sistema: Os espaços livres públicos de recreação e de conservação em Campo Grande, MS. Tese (Doutorado) - Faculdade de Arquitetura e Urbanismo da Universidade de São Paulo. São Paulo, 2008.

WHYTE, William. The social life of small urban spaces. NovaYork: Project for public spaces, 1988.

WILLIAMSON, Thad. Sprawl, justice, and citizenship: The civic costs of the american way of life. Nova York: Oxford University Press, 2010. 
Silvio Soares Macedo, Eugenio Fernandes Queiroga, Fany Cutcher Galender, Ana Cecília de Arruda Campos, Vanderli Custódio, Helena Degreas, Fabio Mariz Gonçalves 